\title{
María Pita en el teatro. Las obras dramáticas de Antonio Valladares de Soto- mayor y Francisco Robello y Vasconi ${ }^{1}$
}

\author{
Federico Juan Briante Benítez ${ }^{2}$
}

Recibido: 3 de setembro de 2018 / Aceptado: 15 de abril de 2020

Resumen. En este artículo, abordamos el análisis de dos textos teatrales que versan sobre la intervención de María Pita en el cerco inglés de A Coruña en el año 1589. Uno de ellos es la comedia Defensa de La Coruña por la heroica María Pita, compuesta por Antonio Valladares de Sotomayor, célebre dramaturgo gallego del siglo XVIII y autor de una amplia y variada producción teatral. El otro texto, que había sido prácticamente ignorado hasta el momento, se titula María Pita o la heroína de Galicia; la autoría de este drama histórico la atribuimos a Francisco Robello y Vasconi, un actor del siglo XIX del que apenas se tenían noticias, de ahí que nos hayamos visto obligados a reconstruir su biografía, en la medida en que ha sido posible. Una comparación entre la comedia de Valladares y el drama de Robello deja entrever diferencias en varios ámbitos, como, por ejemplo, el ideológico.

Palabras clave: A Coruña; María Pita; teatro; Valladares de Sotomayor; Robello y Vasconi.

\section{[gal] María Pita no teatro. As obras dramáticas de Antonio Valladares de Soto- mayor e Francisco Robello y Vasconi}

Resumo. Neste traballo, abordamos a análise de dous textos teatrais que versan sobre a intervención de María Pita no cerco inglés da Coruña no ano 1589. Un deles é a comedia Defensa de La Coruña por la heroica María Pita, composta por Antonio Valladares de Sotomayor, soado dramaturgo galego do século XVIII e autor dunha ampla e variada produción teatral. $\mathrm{O}$ outro texto, que fora practicamente ignorado ata o momento, titúlase María Pita o la heroína de Galicia; a autoría deste drama histórico atribuímola a Francisco Robello y Vasconi, un actor do século XIX do que apenas se tiñan noticias, por iso é polo que nos viramos obrigados a reconstruír a súa biografía, na medida en que foi posible. Unha comparación entre a comedia de Valladares e o drama de Robello deixa entrever diferenzas en varios ámbitos, como, por exemplo, o ideolóxico.

Palabras chave: A Coruña; María Pita; teatro; Valladares de Sotomayor; Robello y Vasconi.

\section{[en] María Pita in the Theatre. The Dramatic Works of Antonio Valladares de So- tomayor and Francisco Robello y Vasconi}

\begin{abstract}
In this article, we analyze two theatrical texts that deal with María Pita's intervention in the English siege of A Coruña in 1589. One of them is the comedy Defensa de La Coruña por la heroica María Pita, composed by Antonio Valladares de Sotomayor, famous Galician playwright of the eighteenth-century and author of a wide and varied theatrical production. The other text, which had been practically ignored so far, is called María Pita o la heroina de Galicia; we attribute the authorship of this historical drama to Francisco Robello y Vasconi, a nineteenth-century actor of whom we barely had news, hence we have been forced to reconstruct his biography, to the extent that it has been possible. A comparison between Valladares's comedy and Robello's drama reveals differences in various areas, such as the ideological one. Keywords: A Coruña; María Pita; Theatre; Valladares de Sotomayor; Robello y Vasconi.

Sumario. 1. Introducción. 2. Antonio Valladares de Sotomayor y Francisco Robello y Vasconi. Vida y obra. 3. María Pita, una vida apasionante. 4. La Defensa de La Coruña por la heroica María Pita (1784) y María Pita o la heroína de Galicia (1833). 5. Conclusiones. 6. Referencias bibliográficas.
\end{abstract}

1 Para la realización de este trabajo he contado con la financiación del V Plan Propio de Investigación de la Universidad de Sevilla.

2 Universidad de Sevilla. Departamento de Literatura Española e Hispanoamericana.

Correo-e: fbriante@us.es; http://orcid.org/0000-0002-6302-710X. 
Como citar: Briante Benítez, F. J. (2020): "María Pita en el teatro. Las obras dramáticas de Antonio Valladares de Sotomayor y Francisco Robello y Vasconi", en Madrygal. Revista de Estudios Gallegos 23, pp. 97-120.

\section{Introducción}

Hablar sobre María Pita es reivindicar el papel de las mujeres en la historia de España, un papel que, en muchos casos, se olvida o menosprecia. No solo por su activa participación en la defensa de la ciudad de A Coruña en el año 1589 , sino por toda su trayectoria vital, esta gallega constituye, a nuestro parecer, un ejemplo de superación admirable, en una época en que ser mujer no resultaba nada fácil. En este artículo nos acercamos a la figura de María Pita desde un punto de vista literario, a través de dos obras dramáticas que tienen como protagonista a la heroína coruñesa. Nos referimos a la Defensa de La Coruña por la heroica María Pita de Antonio Valladares de Sotomayor y María Pita o la heroína de Galicia de Francisco Robello y Vasconi.

Nuestro trabajo se divide en tres bloques fundamentales: en el primero, esbozamos la biografía y la producción literaria de los dos escritores que aquí nos ocupan y, en el segundo, recordamos la historia de María Pita. Con ello se busca proporcionar toda la información necesaria para el estudio comparativo que realizamos, en el tercer bloque, entre la comedia de Valladares y el drama de Robello.

\section{Antonio Valladares de Sotomayor y Fran- cisco Robello y Vasconi. Vida y obra}

La Defensa de La Coruña por la heroica María Pita fue compuesta por uno de los dramaturgos más prolíficos del siglo XVIII, Antonio Valladares de Sotomayor. Este nació en Rianxo (A Coruña) el 30 de julio de 1737, en el seno de una familia hidalga. Sus padres, Diego José Valladares y Sotomayor y Ángela Domínguez de Noboa, vivían probablemente de forma modesta, pues, aunque el primero trabajaba como escribano real, el matrimonio tenía doce hijos a los que mantener. La familia debió de permanecer en Rianxo hasta 1745; a partir de ese momento no se sabe nada de Valladares hasta el año 1760, en que supuestamente llegó a
Madrid, donde empezaría a labrarse un futuro como dramaturgo (Herrera Navarro 2005: 429-447). En 1785 formaba parte, como socio numerario, de la Sociedad de Amigos del País de Osuna; en este municipio sevillano residiría, como mínimo, dos años, en los que ejerció como administrador de la Renta de Correos (Soheim 1993: 6-7). En abril de 1787 empezó a publicar el Semanario Erudito, un periódico cuya finalidad consistía en dar a conocer obras relacionadas con la literatura, la política y la historia de España, entre otras materias ${ }^{3}$ (Sutherland-Meier 2010: 598-599; 2013: 498). Tras cuatro años de existencia, el Semanario Erudito dejó de editarse en febrero de 1791, debido a la prohibición de la prensa periódica (salvo el Diario de Madrid) dictaminada por Floridablanca, quedando Valladares en la penuria económica y con numerosas deudas. No obstante, el escritor gallego no se amilanó, sino que siguió luchando en los años siguientes: en 1797, emprendería una novela por entregas, titulada La Leandra; en abril de 1804, sacó a la luz el Almacén de frutos literarios inéditos de los mejores autores, publicación que sería prohibida a finales de ese mismo mes; finalmente, en 1815, comenzaron a distribuirse por suscripción los dos primeros tomos de la obra miscelánea Tertulias de invierno en Chinchón, de la que se publicaron dos tomos más en 1820, año en que probablemente murió el autor (Soheim 1993: 17-42).

Además de sus incursiones en el periodismo y en la narrativa, Valladares también mostró interés por la lírica: como ejemplos podríamos mencionar el romance Verdadera y gloriosa relación ${ }^{4}$ (1766), en el que se ensalza la reacción de Carlos III ante el motín de Esquilache, y la Colección de seguidillas o cantares, de los más instructivos y selectos (1799), que figura "entre las primeras recopilaciones folklóricas de nuestro país" (Gómez Rodríguez 1998-1999: 152). Ahora bien, es el teatro el género literario al que, indudablemente, se dedicó con más ahínco; sus obras dramáticas superan el centenar; escribió comedias de magia (Esposa y trono a un tiempo y el mágico de Serván [1781], El mágico del Mogol [1782], Samir y Nircea [1793]...) $)^{5}$, comedias heroicas (Faltar a padre y amante por obedecer al Rey.

Sobre este periódico, véase también Baldaquí Escandell 1984.

Este romance puede consultarse en Sutherland-Meier 2009: 108-110.

Sobre las comedias de magia de Valladares, véase Soheim 1993: 329-376. 
La Etrea [1778], Lealtad, traición e inocencia o Sifiro y Etolia [1782], A una grande heroicidad, pagar con otra más grande [1782].... $)^{6}$, sentimentales (El fabricante de paños o el comerciante inglés [1783], El vinatero de Madrid [1784], Las vivanderas ilustres [1788], etc.) $)^{7}$, patrióticas (El triunfo mayor de España por el gran lord Wellington [1813], Sitio de Calatayud por el Marte Empecinado [1814] o Nuestro rey Fernando VII en el complot de Bayona [1814]) ${ }^{8}$; alguna que otra tragedia (Sólo vence la traición un constante corazón. La Edubige en Persia [1781], La Elmira [1788] y Eduardo III [?] $)^{9}$; y, por si fuera poco, veintidós sainetes (El apoderado de Indias [1779], Amigo verdadero [1792], Los criados embusteros $[1805] \ldots)^{10}$.

En resumidas cuentas, la vida y la obra de Valladares son las de un luchador nato, alguien que, pese a las dificultades (sobre todo, económicas) a las que tuvo que hacer frente, nunca renunció a vivir de la letras (Soheim 1998: 296; Herrera Navarro 2005: 448; Sutherland-Meier 2013: 502), contribuyendo, de este modo, a la profesionalización del oficio de escritor ${ }^{11}$.

En cuanto al otro texto del que vamos a tratar en este trabajo, María Pita o la heroína de Galicia, su autoría no estaba tan clara cuando empezamos a estudiarlo. Según nos indica el único manuscrito que se conserva de ella (en la Biblioteca Nacional de España ${ }^{12}$ ), esta obra es "composición original de Francisco Robello, $1^{\text {er }}$ actor de carácter anciano del teatro de La Coruña. Año de 1833" (fol. 1r) ${ }^{13}$. Este nombre nos hizo pensar, en un primer momento, en Francisco Robello y Vasconi, un actor y dramaturgo del siglo XIX. En cambio, tras consultar algunos catálogos e historias de la literatura, descubrimos que María Pita o la heroína de
Galicia no figuraba entre las piezas dramáticas de Robello y Vasconi; es lo que observamos, por ejemplo, en Julio Cejador y Frauca (1972: 177 y 422) o en Tomás Rodríguez Sánchez (1994: 488 y 497), quienes atribuyen esta obra a un tal Francisco Rebollo; sobre este último, a más de que no hemos encontrado ningún actor o dramaturgo decimonónico con este nombre (de hecho, en los citados trabajos de Cejador y Frauca y de Rodríguez Sánchez, María Pita... es la única obra que se le asigna a ese hipotético autor), su apellido (Rebollo) no coincide exactamente con el del escritor mencionado en nuestro manuscrito (Robello). Así pues, la opción más probable seguía siendo la de Robello y Vasconi, aunque, para salir de dudas, necesitábamos averiguar si este había ejercido como actor en A Coruña en el año 1833 y, por tanto, si era él la persona a la que se refería el manuscrito de la Biblioteca Nacional. Esto no fue tarea fácil pues la figura de Robello y Vasconi no parece haber llamado la atención de la crítica literaria, por lo que su biografía estaba repleta de lagunas, que hemos procurado llenar con la presente investigación, para lo que nos han resultado de gran ayuda la documentación de los archivos municipales $y$, sobre todo, la prensa de la época.

Aunque desconocemos su lugar y fecha exacta de nacimiento, Francisco Robello y Vasconi debió de nacer en 1802, ya que, en la dedicatoria que hace a Eugenia de Montijo de su poema La traición o Judas y López, fechada en Madrid el 16 de septiembre de 1867, el autor afirma lo siguiente: "Dígnese Vuestra Majestad disculpar con su instintiva benevolencia la osadía de este modesto escritor, anciano de 65 años y enfermo habitual (...)" (Robello y Vasconi 1867: s.p.; la cursiva es mía).

Acerca de las comedias heroicas, véase Soheim 1993: 97-197.

Véanse García Garrosa 1991 y Soheim 1993: 199-321; 1996b.

Véase Sutherland-Meier 2014: 427.

Sobre las tragedias, véase Soheim 1993: 378-425.

La producción sainetística de Valladares ha sido estudiada por Soheim 1993: 427-466; 1996 a.

Sobre este asunto, véase Álvarez Barrientos 1992.

2 Biblioteca Nacional de España, MSS/17427. Disponible en: http://bdh-rd.bne.es/viewer.vm?id=0000217615\&page=1 [consulta: 09/03/2018].

13 Para las citas de este drama, utilizamos siempre el manuscrito de la Biblioteca Nacional de España mencionado en la nota anterior, que, como se dijo más arriba, es el único testimonio existente sobre dicho drama, hasta donde sabemos. En cuanto a los criterios aplicados en la transcripción de las citas textuales de esta obra, así como de todas las demás citas que aparezcan en nuestro artículo, conviene indicar que desarrollamos las abreviaturas -siempre que estas no sean demasiado corrientes-y modernizamos la ortografía, aunque se respetan las características morfosintácticas de los textos reproducidos. De este modo, procuramos facilitar la comprensión de dichos textos pero, al mismo tiempo, conservar parte de su idiosincrasia. 
Se ganó la vida como actor de carácter anciano en varios teatros de la geografía española. La primera noticia que hemos hallado en la prensa sobre este quehacer profesional se remonta a 1831, cuando la revista Cartas Españolas nos lo presenta formando parte de la compañía de declamación, música y baile que ese mismo año había constituido Andrés Toribio para los Reales Sitios ${ }^{14}$. La siguiente referencia de la que tenemos constancia nos lleva al mes de abril de 1833, a la ciudad de A Coruña, donde Robello y Vasconi tenía un contrato como actor de carácter anciano para la temporada cómica que estaba a punto de iniciarse, según nos informa La Revista Española ${ }^{15}$. Si nos damos cuenta, estos datos coinciden con los que veíamos en el manuscrito de María Pita o la heroína de Galicia, lo que confirmaría que fue Robello y Vasconi quien escribió este drama en 1833. Es más, por aquel entonces, la ciudad herculina solo contaba con un teatro en activo, el de Variedades ${ }^{16}$, situado en la calle de la Franja y propiedad de Bernardo del Río (Sánchez García 1992: 137-141; 1992-1993: 247), de ahí que en nuestro manuscrito se hable "del teatro de la Coruña", en singular y sin mayor especificación.

Cuatro años más tarde, en noviembre de 1837, Robello presenta al ayuntamiento de A Coruña una serie de proposiciones con el fin de obtener un permiso para la formación de una compañía dramática. El expediente, que se conserva en el Archivo Municipal de A Coruña (en adelante, $\mathrm{AMC})^{17}$, resulta muy revelador, por lo que merece la pena detenerse en él, aunque solo sea brevemente.

Entre la información de carácter biográfico que Robello nos facilita en este documento, se encuentra la relativa a su edad: "Me puedo jactar de una honradez sin tacha y no interrumpida en los 36 años que cuento de edad" (s. fol.). Gracias a estas palabras, es posible determinar con mayor precisión la fecha de nacimiento que ofrecíamos más arriba: si Robello contaba con 36 años cuando redactó el expediente del AMC (firmado el 2 de noviembre de 1837) y en la dedicatoria a Eugenia de Montijo (fechada el 16 de septiembre de 1867) -vista más arriba-él se presentaba con 65 años, su nacimiento tuvo que producirse en las fechas comprendidas entre el 16 de septiembre y el 2 de noviembre de 1801 .

Tampoco hemos de pasar por alto lo que dice acerca de su formación académica: "Conociendo el exquisito gusto de este ilustrado público y teniendo yo algunas nociones de literatura adquiridas con el estudio de Humanidades, Filosofía y dos años de Leyes en las universidades de Valencia y Zaragoza (...)" (s. fol.). La adquisición de estos conocimientos colocaría a Robello y Vasconi en una posición privilegiada en relación a la gran masa de los actores españoles del momento, quienes, en líneas generales, carecían de una instrucción básica, como apunta Llergo Ojalvo:

La situación de los actores no era mucho mejor que el estado de los teatros. Sin educación, sin estudios de ningún tipo, ni siquiera nociones básicas de gramática castellana, ni bellas artes, ni historia; sin lecturas previas de poetas clásicos o modernos, sin conocimientos de caracteres diversos, sin ninguna memoria y con una serie de tópicos impostados desde la propia escena para enfrentarse a la representación, así podía resumirse la condición de un actor prototípico de los años 20 del siglo XIX. (2007: 36)

Es en la década de los veinte cuando Robello inicia su trayectoria como actor, lo que se deduce del expediente que estamos comentando: “(...) y a esto contestaré que trece años llevo, por vicisitudes políticas que debían haber cesado para mí, en el ejercicio artístico dramáti$c o$ " (s. fol.; la cursiva es mía). Por el momento no entraremos a aclarar a qué "vicisitudes políticas" se está refiriendo aquí el autor, ya que este punto se abordará más adelante.

Aparte de lo que llevamos comentado, el expediente del AMC también arroja luz sobre su concepción del mundo de Talía; así, Robello se compromete a hacer "desaparecer algunas rancias y envejecidas costumbres que existen en la práctica de los espectáculos" (s. fol.) y a

14 Cartas Españolas (marzo-junio de 1831: p. 22). Disponible en: http://hemerotecadigital.bne.es/issue.vm?id=0003 839364\&search=\&lang=es [consulta: 02/04/2018].

15 La Revista Española (16 de abril de 1833: p. 3). Disponible en: http://hemerotecadigital.bne.es/issue.vm?id=0003 594528\&search=\&lang=es [consulta: 02/04/2018].

16 Para más información sobre los teatros en A Coruña y, en general, en Galicia, pueden verse, por ejemplo, los trabajos de Soraluce Blond 1988 y de Sánchez García 1993.

17 Archivo Municipal de A Coruña, caixa 8429 (Expedientes de goberno e administración do teatro). Expreso mi agradecimiento al personal del Archivo por su ayuda y colaboración inestimables. 
"mejorar en lo posible el adorno escénico" (s. fol.). Además, solicita al ayuntamiento "protección a este ramo de la administración e instrucción pública" (s. fol.). Con estas ideas (concepción del teatro como una herramienta educativa, que ha de ser custodiada por el poder político; preocupación por la mejora del aparato escénico, etc.), Robello y Vasconi parece abogar por una renovación de la escena española, una actitud que lo sitúa en línea con los postulados de grandes e influyentes personajes de la centuria inmediatamente anterior, como el corregidor ilustrado José Antonio de Armona ${ }^{18}$.

Finalmente, Robello y Vasconi no logró el permiso deseado para la formación de su compañía, lo que pudo motivar que el autor abandonara A Coruña, pues en 1839 lo encontramos trabajando en el teatro Buena-Vista de Madrid, situado en la calle de la Luna (actual plaza de Santa María Soledad Torres Acosta). Nuestro dramaturgo formaría parte del elenco de comediantes que actuaban asiduamente en ese teatro hasta, por lo menos, principios del mes de mayo de 1839; así nos lo confirman distintos periódicos y/o revistas de la época, como pasamos a resumir a continuación.
El 6 de abril de 1839, Robello interviene en La huérfana de Bruselas, en el papel del Abate L'Épée ${ }^{19}$. El día 8 figura en las comedias Las capas y Los primeros amores ${ }^{20}$ y el 11 en Acertar errando o el cambio de diligencias ${ }^{21}$. Dos días después, actúa en La conjuración de Venecia, famoso drama de Martínez de la Rosa que se mantuvo en cartel durante cuatro días segui$\operatorname{dos}^{22}$. Tras un receso el 17 de abril, Robello sube nuevamente al escenario del teatro Buena-Vista el 18 y 19, para representar la obra Los asesinos de Florencia o La Quinta de Paluzzzi23. "A petición de varias personas que las veces anteriores se han quedado sin billetes por la pequeña localidad del teatro" 24 , La conjuración de Venecia se vuelve a reponer el 21 de abril, también con la intervención de Robello. A este lo vemos actuar una vez más, el día 23, en las comedias El segundo año o ¿quién tiene la culpa? y La casualidad a media noche ${ }^{25}$, y el $27^{26}$ y $28^{27}$ en El Trovador y en Otro diablo predicador o el liberal por fuerza. Robello cierra el mes de abril e inicia el de mayo con su actuación en el drama victorhuguiano Angelo, tirano de $\mathrm{Padua}^{28}$. La última función del teatro Buena-Vista en la que sabemos con seguridad

18 Véase Armona y Murga 2007.

19 Diario de avisos de Madrid (6 de abril de 1839: p. 4). Disponible en: http://hemerotecadigital.bne.es/issue.vm? $\mathrm{id}=0002952247$ \&page=1\&search=\&lang=es [consulta: 10/04/2018]. Diario de avisos de Madrid (7 de abril de 1839: p. 3). Disponible en: http://hemerotecadigital.bne.es/issue.vm?id=0002952299\&search=\&lang=es [consulta: 10/04/2018]. El Eco del Comercio (12 de abril de 1839: p. 4). Disponible en: http://hemerotecadigital.bne.es/issue. $\mathrm{vm}$ ?id=0003107035\&search=\&lang=es [consulta: $12 / 04 / 2018]$.

20 Diario de avisos de Madrid (8 de abril de 1839: p. 4). Disponible en: http://hemerotecadigital.bne.es/issue.vm?id= 0002952343\&page=2\&search=\&lang=es [consulta: $12 / 04 / 2018$ ].

21 Diario de avisos de Madrid (11 de abril de 1839: p. 4). Disponible en: http://hemerotecadigital.bne.es/issue.vm?id $=0002952493 \&$ search $=\&$ lang=es [consulta: $12 / 04 / 2018]$.

22 Diario de avisos de Madrid (13 de abril de 1839: p. 4). Disponible en: http://hemerotecadigital.bne.es/issue.vm?id=00 02952608\&search=\&lang=es [consulta: 15/04/2018]. Diario de avisos de Madrid (14 de abril de 1839: p. 4). Disponible en: http://hemerotecadigital.bne.es/issue.vm?id=0002952701\&search=\&lang=es [consulta: 15/04/2018]. Diario de avisos de Madrid (15 de abril de 1839: p. 4). Disponible en: http://hemerotecadigital.bne.es/issue.vm?id=0002952 787\&search=\&lang=es [consulta: 15/04/2018]. Diario de avisos de Madrid (16 de abril de 1839: p. 4). Disponible en: http://hemerotecadigital.bne.es/issue.vm?id=0002952823\&page=1\&search=\&lang=es [consulta: 16/04/2018].

23 Diario de avisos de Madrid (18 de abril de 1839: p. 4). Disponible en: http://hemerotecadigital.bne.es/issue.vm? id=0002952855\&search=\&lang=es [consulta: 16/04/2018]. Diario de avisos de Madrid (19 de abril de 1839: p. 4). Disponible en: http://hemerotecadigital.bne.es/issue.vm?id=0002952864\&page=1\&search=\&lang=es [consulta: 16/04/2018].

24 Diario de avisos de Madrid (21 de abril de 1839: p. 4). Disponible en: http://hemerotecadigital.bne.es/issue.vm?id $=0002952894 \&$ page $=4 \&$ search=\&lang=es [consulta: 18/04/2018].

25 Diario de avisos de Madrid (23 de abril de 1839: p. 4). Disponible en: http://hemerotecadigital.bne.es/issue.vm?id $=0002952920 \&$ page $=1 \&$ search=\&lang=es [consulta: 18/04/2018].

26 Diario de avisos de Madrid (27 de abril de 1839: p. 4). Disponible en: http://hemerotecadigital.bne.es/issue.vm?id=0 002952973\&page=2\&search=\&lang=es [consulta: 18/04/2018]. El Correo Nacional (27 de abril de 1839: p. 4). Disponible en: http://hemerotecadigital.bne.es/issue.vm?id=0026265660\&search=\&lang=es [consulta: 19/04/2018].

27 Diario de avisos de Madrid (28 de abril de 1839: p. 4). Disponible en: http://hemerotecadigital.bne.es/issue.vm?id $=0002953018 \&$ search=\&lang=es [consulta: $20 / 04 / 2018]$.

28 Diario de avisos de Madrid (30 de abril de 1839: p. 4). Disponible en: http://hemerotecadigital.bne.es/issue.vm?id= 0002953095\&search=\&lang=es [consulta: 20/04/2018]. Diario de avisos de Madrid (1 de mayo de 1839: p. 4). Disponible en: http://hemerotecadigital.bne.es/issue.vm?id=0002953107\&search=\&lang=es [consulta: 20/04/2018]. 
que participó fue la que tuvo lugar en la noche del 7 de mayo ${ }^{29}$, cuando se escenificó la comedia Todo y nada o el veleta. En su anuncio del jueves 9 de mayo, el Diario de avisos de Madrid no menciona a Robello entre los actores que ponen en escena La huérfana de Bruselas, obra programada para ese día y que nuestro autor ya había representado anteriormente -recordemos. Algo más de información al respecto ofrece El Correo Nacional, que nos avisa de que "por indisposición de D. Francisco Robello, primer actor de carácter anciano, tendrá el honor de presentarse a desempeñar su papel D. Ceferino Hernández, confiando en la indulgencia de un público tan ilustrado" 30 .

A partir de este momento, se pierde la pista de Robello hasta septiembre de 1840. Entonces, distintos periódicos (El Corresponsal ${ }^{31}, E l$ Eco del Comercio $^{32}$ y El Católico ${ }^{33}$ ) presentan al autor interviniendo en la oleada de revueltas progresistas que recorrieron España, desde que el 1 de septiembre el ayuntamiento de Madrid se rebelara contra las medidas que estaban tomando los moderados, en el gobierno desde las elecciones generales de enero de ese año ${ }^{34}$. Estas sublevaciones desembocaron, finalmente, en el nombramiento de Baldomero Espartero, general comprometido con la causa progresista, como presidente del Consejo de Ministros y con el exilio a París de la reina regente María Cristina ${ }^{35}$.
Durante la etapa de gobierno de Espartero (1840-1843), Robello ejerció distintas responsabilidades en política local ${ }^{36}$.

En 1843-1844, con la marcha al exilio del duque de la Victoria, que había encarnado el "mito de la revolución liberal" (Marchena Domínguez 1995: 91), y la vuelta al poder de los moderados, es probable que Robello, desilusionado, dejara el primer plano de la política. El silencio de la prensa al respecto no nos permite pensar lo contrario. Sí nos llegan, en cambio, noticias referentes a la actividad literaria del autor en estos años: por ejemplo, el 25 de mayo de 1845, el Semanario Pintoresco Español anuncia la representación de su drama Dos venganzas y un castigo en el teatro Variedades de Madrid ${ }^{37}$. Asimismo, el periódico El Clamor Público (17 de octubre de 1845) publica una escueta, aunque elogiosa, reseña del primer tomo de su novela La criolla y los jesuitas $^{38}$. Aun así, algunas de las iniciativas literarias y/o editoriales emprendidas por Robello en esta época se verían torpedeadas por la acción del gobierno moderado, en el poder desde 1844 hasta 1854 (la conocida "Década Moderada" 39 ), hecho este del que dan cuenta los periódicos El Espectador ${ }^{40}$, La Esperan$z a^{41}$ y el Diario Constitucional de Palma de Mallorca ${ }^{42}$; estos nos hablan del proyecto de Robello de sacar adelante, junto con otro socio,

29 Diario de avisos de Madrid (7 de mayo de 1839: p. 4). Disponible en: http://hemerotecadigital.bne.es/issue.vm?id $=0002953177 \&$ page $=1 \&$ search=\&lang=es [consulta: $20 / 04 / 2018]$.

30 El Correo Nacional (9 de mayo de 1839: p. 4). Disponible en: http://hemerotecadigital.bne.es/issue.vm?id=00262 65848\&search=\&lang=es [consulta: 20/04/2018].

31 El Corresponsal (7 de septiembre de 1840: p. 4). Disponible en: http://hemerotecadigital.bne.es/issue.vm?id=0029 051673\&search=\&lang=es [consulta: 20/04/2018].

32 El Eco del Comercio (8 de septiembre de 1840: p. 2). Disponible en: http://hemerotecadigital.bne.es/issue.vm?id= 0003130775\&search=\&lang=es [consulta: 20/04/2018].

33 El Católico (9 de septiembre de 1840: p. 3). Disponible en: http://hemerotecadigital.bne.es/issue.vm?id=00031681 76\&search=\&lang=es [consulta: 20/04/2018].

34 Entre dichas medidas, que, a juicio de los progresistas, buscaban recortar los derechos alcanzados en la Constitución de 1837, se encontraba la polémica Ley de Ayuntamientos, que "representaba la imposición de un sistema de censo reducido sobre la base de las contribuciones de los vecinos" (Casals Bergés 2001: 25).

35 Véase Díaz Marín 2006.

36 El Corresponsal (26 de octubre de 1840: p. 3). Disponible en: http://hemerotecadigital.bne.es/issue.vm?id=0029051 916\&search=\&lang=es [consulta: 21/04/2018]. Fray Gerundio, boletín de noticias (27 de enero de 1842: p. 4). Disponible en: http://hemerotecadigital.bne.es/issue.vm?id=0029873060\&search=\&lang=es [consulta: 21/04/2018]. El Eco del Comercio (14 de febrero de 1842: p. 1). Disponible en: http://hemerotecadigital.bne.es/issue.vm?id=000 3154422\&search=\&lang=es [consulta: $21 / 04 / 2018$ ].

37 Semanario Pintoresco Español (25 de mayo de 1845: p. 8). Disponible en: http://hemerotecadigital.bne.es/issue.vm ?id=0003121548\&search=\&lang=es [consulta: 02/05/2018].

38 El Clamor Público (17 de octubre de 1845: p. 3). Disponible en: http://hemerotecadigital.bne.es/issue.vm?id=0002 623708\&search=\&lang=es [consulta: 02/05/2018].

39 Sobre este período de la historia de España, véase Díaz Marín 1997.

40 El Espectador (18 de julio de 1845: p. 3). Disponible en: http://hemerotecadigital.bne.es/issue.vm?id=0003635341 \&search=\&lang=es [consulta: 02/05/2018].

41 La Esperanza (21 de julio de 1845: p. 4). Disponible en: http://hemerotecadigital.bne.es/issue.vm?id=0001811427 \&search=\&lang=es [consulta: 03/05/2018].

42 Diario Constitucional de Palma de Mallorca (10 de agosto de 1845: p. 1). Disponible en: http://hemerotecadigital. bne.es/issue.vm?id=0004435007\&search=\&lang=es [consulta: 03/05/2018]. 
una publicación satírico-política que se titularía Los Dos Veteranos, algo que nunca fue posible debido a la aprobación, el 6 de julio de 1845, del Real Decreto sobre libertad de imprenta.

Esta deriva represiva del gobierno moderado de Narváez, que se recrudece con el estallido de la revolución en Francia, y la situación de crisis económica, entre otros factores, producen una cadena de levantamientos progresistas por toda España entre marzo y mayo de 1848; Madrid, Barcelona, Valencia, Sevilla o Murcia fueron algunos de los escenarios de estas revueltas, que el ejecutivo logró sofocar. Como consecuencia de los desórdenes provocados, muchos sufrieron destierro en Filipinas, África, Canarias o Baleares (Lida 2000: 331); a este último archipiélago (concretamente a la isla de Ibiza) llegó confinado Robello en junio de 1848 (Vallès Costa 2010), lo que indicaría que nuestro autor había tomado parte, de alguna u otra forma, en las protestas antigubernamentales de marzo-mayo. El propio Robello se refiere años más tarde a los motivos de este destierro en la dedicatoria de su obra La unión carlo-polaca:

No estos altos e importantes cargos que tan dignamente desempeña usted me estimulan a dedicarle el presente juguete cómico. ¿Se acuerda usted, amigo mío, de la isla de Ibiza, de aquella isla hospitalaria cuyos virtuosos y sencillos habitantes tan bien nos recibieron en el año de 1848, cuando la mano de la más inaudita arbitrariedad nos alejó de nuestras familias? ¿Se acuerda usted de tantas penas, de tantos sinsabores como hemos experimentado por defender la causa santa de los libres? (Robello y Vasconi 1856: s. p.)

Como vemos, Robello no guardaba un recuerdo del todo negativo de los nueve meses que permaneció en Ibiza, un lugar al que siempre defendería ${ }^{43}$ por la acogida que le habían tributado sus habitantes. Es más, durante su estancia en la isla, hizo amigos y publicó varios artículos en El Ebusitano, el primer periódico semanal ibicenco (Vallès Costa 2010; Tateishi 2010).

En junio de 1850, y después de haber estado retirado de ellas durante diez años, Robello vuelve a las tablas para interpretar, en el teatro Español, a Juan Morosini en La conjuración de Venecia. De este regreso a los escenarios, que se produce gracias al apoyo de Julián Romea (director del citado teatro $)^{44}$, se hacen eco diversos periódicos (La Época ${ }^{45}$, La Nación ${ }^{46}$, el Diario de avisos de Madrid ${ }^{47}$, La Patria ${ }^{48}$, etc.), pero hay uno en el que nos interesa incidir, ya que no solo ayuda a confirmar y/o puntualizar algunos datos de la biografía del autor que ya hemos aducido líneas más arriba, sino que, lo más importante, añade información nueva al respecto; nos referimos al periódico El Observador:

Esta noche se ejecuta en el teatro Español el drama del señor Martínez de la Rosa titulado $\mathrm{La}$ conjuración de Venecia, en el que se presentará a desempeñar el papel de Juan Morosini don Francisco Robello, escritor conocido bajo el pseudónimo del tío Fi[d]el y que hace diez años que no ha pisado la escena. Dedicóse al teatro en 1825 , de resultas de no haber podido concluir la carrera de abogado que había emprendido, por los compromisos que contrajo siendo muy joven en los sucesos políticos del 20 al 23. Se retiró del teatro en 1840 bajo los más brillantes auspicios y en 1845 empezó de nuevo a serle contraria la suerte, hasta que en 1848 concluyó por arruinarle completamente $(\ldots)^{49}$

El dato nuevo que nos ofrece este periódico es que nuestro autor estuvo implicado en "los sucesos políticos del 20 al 23", es decir, en el Trienio Liberal. Esto le impidió concluir sus estudios de Derecho (estudios de los que ya teníamos constancia por el expediente del AMC -recordemos-: "dos años de Leyes en las universidades de Valencia y Zaragoza [...]"), algo que, por otra parte, no nos debe extrañar

43 Véanse Vallès Costa 2010; Navas Sánchez-Elez y Ribera Llopis 2015: 78 y 92; Torres Molina 2018.

44 El Observador (29 de mayo de 1850: p. 4). Disponible en: http://hemerotecadigital.bne.es/issue.vm?id=00035342 51\&search=\&lang=es [consulta: 03/05/2018].

45 La Época (19 de junio de 1850: p. 4). Disponible en: http://hemerotecadigital.bne.es/issue.vm?id=0000012224\&s earch=\&lang=es [consulta: 03/05/2018].

46 La Nación (19 de junio de 1850: p. 4). Disponible en: http://hemerotecadigital.bne.es/issue.vm?id=0026579852\&s earch=\&lang=es [consulta: 05/05/2018].

47 Diario de avisos de Madrid (20 de junio de 1850: p. 4). Disponible en: http://hemerotecadigital.bne.es/issue.vm?id $=0000216355 \&$ search $=\&$ lang=es [consulta: 05/05/2018].

48 La Patria (23 de junio de 1850: p. 4). Disponible en: http://hemerotecadigital.bne.es/issue.vm?id=0026782859\&s earch=\&lang=es [consulta: 05/05/2018].

49 El Observador (20 de junio de 1850: p. 3). Disponible en: http://hemerotecadigital.bne.es/issue.vm?id=000353468 9\&search=\&lang=es [consulta: 05/05/2018]. 
teniendo en cuenta que, cuando Fernando VII regresa al poder en 1823 , toma duras represalias contra los liberales ${ }^{50}$. De este modo, ante la imposibilidad de acabar su formación como abogado, Robello empezó a dedicarse al teatro, ocupación que dejaría en torno a 1840 "bajo los más brillantes auspicios"; con estas últimas palabras El Observador estaría refiriéndose a las expectativas de éxito que supuso para Robello, en cuanto progresista, el triunfo de Espartero en 1840; de hecho, ya vimos que, en los años de gobierno del duque de la Victoria (18401843), nuestro dramaturgo desempeñó responsabilidades políticas, una buena racha que terminaría con la llegada al poder de los moderados (1844-1854); concretamente, el periódico apostilla que "en 1845 empezó de nuevo a serle contraria la suerte" (recordemos que en ese año había sido rechazado el proyecto de Robello de publicar el periódico Los Dos Veteranos).

En relación a su participación en el Trienio Liberal, el periódico progresista El Clamor Público saca a la luz, el 5 de octubre de 1851, un comunicado de Robello en el que este lamenta la muerte del general Ena, que fue entre 1820 y 1823 cabo segundo de la tercera compañía del primer batallón de la Milicia Nacional Voluntaria de Zaragoza, batallón en cuya segunda compañía ejerció Robello como sargento primero, según él mismo afirma al pie de dicho comunicado $^{51}$. Así pues, queda claro el papel que adoptó durante el Trienio Liberal: como integrante de la Milicia Nacional, un "órgano cívico militar encargado de salvaguardar el constitucionalismo" (Calles Hernández 2015: 15), Robello se posicionaba, en plena juventud, a favor de las ideas liberales y en contra del absolutismo fernandino.
Hecho este breve pero necesario excurso, volvemos de nuevo a 1850, año en que, como dijimos más arriba, Robello retoma su profesión de actor interviniendo en La conjuración de Venecia. Esta obra se mantuvo varios días en cartel $^{52} \mathrm{y}$, aunque las apreciaciones varían según el periódico que consultemos, algunos fueron especialmente elogiosos con él, como La Época:

El actor D. Francisco Robello, que en la noche de su salida en La conjuración de Venecia desempeñó su papel con cierta timidez, si bien con inteligencia, ha sido estas últimas noches justamente aplaudido, revelando que, como actor de carácter anciano, puede figurar entre los primeros de su clase ${ }^{53}$.

En adelante, Robello continuaría entregado al quehacer literario; por ejemplo, en julio de $1855^{54}$ se estrenaron en el teatro de la Cruz dos de sus piezas dramáticas, La unión carlopolaca o una carta de Bayona y Un fusil del dos de Mayo en 17 de Julio, para celebrar el primer aniversario de la revolución que había provocado la caída del gobierno moderado y el regreso de Espartero (Fuente Monge 2013: 124-126); este último acudió a la representación teatral, en la que fue vitoreada la libertad y en la que muchos de los espectadores vistieron el uniforme de la Milicia Nacional ${ }^{55}$.

Los años finales de la vida de Robello fueron difíciles; estaba enfermo y en la miseria. En 1865 lo encontramos ingresado en el Hospital de los Incurables de Nuestra Señora del Carmen de Madrid, lugar desde el que escribió su poema Las dos Isabeles ${ }^{56}$, como él mismo sugiere en la dedicatoria (fechada el 12 de marzo de 1865) del texto: "Si Vuestra Excelencia acoge benévolo esta mi obrita, redactada en el

50 Sobre las medidas represivas adoptadas, véase Peset Reig 1967.

51 El Clamor Público (5 de octubre de 1851: p. 3). Disponible en: http://hemerotecadigital.bne.es/issue.vm?id=00027 32950\&search=\&lang=es [consulta: 06/05/2018].

52 Diario oficial de avisos de Madrid (24 de junio de 1850: p. 4). Disponible en: http://hemerotecadigital.bne.es/issue. $\mathrm{vm}$ ?id $=0000216446 \&$ search $=\&$ lang $=$ es [consulta: 06/05/2018].

53 La Época (25 de junio de 1850: p. 4). Disponible en: http://hemerotecadigital.bne.es/issue.vm?id=0000012387\&s earch=\&lang=es [consulta: 06/05/2018].

54 Véase Vallejo y Ojeda 2001: 45-46.

55 La Iberia (18 de julio de 1855: p. 4). Disponible en: http://hemerotecadigital.bne.es/issue.vm?id=0001139464\&se arch=\&lang=es [consulta: 06/05/2018].

56 La Correspondencia de España (2 de junio de 1865: p. 1). Disponible en: http://hemerotecadigital.bne.es/issue. vm?id=0000063104\&search=\&lang=es [consulta: 07/05/2018]. La Época (2 de junio de 1865: p. 4). Disponible en: http://hemerotecadigital.bne.es/issue.vm?id=0000200913\&page=4\&search=robello+ribello\&lang=es [consulta: 07/05/2018]. El Pabellón Nacional (2 de junio de 1865: p. 2). Disponible en: http://hemerotecadigital.bne.es/issue. vm?id=0026575300\&page=2\&search=robello+ribello\&lang=es [consulta: 07/05/2018]. La España (4 de junio de 1865: p. 4). Disponible en: http://hemerotecadigital.bne.es/issue.vm?id=0002909596\&search=\&lang=es [consulta: 08/05/2018]. La Regeneración (5 de junio de 1865: p. 3). Disponible en: http://hemerotecadigital.bne.es/issue.vm?id $=0026663751 \&$ search $=\&$ lang=es [consulta: 08/05/2018]. 
estado valetudinario en que me encuentro y en un asilo benéfico, tendré la más grata expansión y el contentamiento de que carezco hace ya largo tiempo" (Robello y Vasconi 1865: 5).

En noviembre de 1866, su estado de salud no había mejorado; La Correspondencia de España nos lo presenta "aquejado de una crónica y penosa enfermedad $\mathrm{y}$, viviendo en la indigencia hace tres años, se ha visto en la necesidad de apelar a los hospitales, habiendo permanecido últimamente en el general de esta corte cuatro meses" 57 .

Es probable que nuestro dramaturgo muriera a finales de esta década de los sesenta del siglo XIX. Los últimos datos que disponemos sobre él son de 1867, cuando se publican sus poemas San Isidro Labrador ${ }^{58}$ y La traición o Judas y López ${ }^{59}$.

En resumen, como hemos tenido ocasión de comprobar a lo largo de estas líneas, Francisco Robello y Vasconi se revela, al igual que Valladares, como una figura harto polifacética; en él se conjugan el desarrollo del periodismo, el interés por la política y la dedicación a la literatura; respecto a esto último, cultivó la narrativa (destaca su novela La criolla y los jesuitas $[1845]^{60}$ ), la lírica (La rosa de más fragancia [1856], Las dos Isabeles [1865], etc.) y, sobre todo, el teatro, género literario con el que estaba sobradamente familiarizado por su trabajo como actor. Sus obras dramáticas (María Pita o la heroína de Galicia [1833], Dos venganzas y un castigo [1845], La unión carlo-polaca o una carta de Bayona [1855] y Un fusil del dos de Mayo en 17 de Julio [1855], entre otras ${ }^{61}$ ) están salpicadas de connotaciones políticas, que solo se entienden a la luz de la trayectoria vital del autor, de ahí que nos hayamos detenido en reconstruir su biografía, sobre la que prácticamente no se sabía nada.

\section{María Pita, una vida apasionante}

Antes de entrar en el análisis comparativo de las dos obras dramáticas que aquí nos interesan, creemos conveniente hacer una breve presentación del personaje histórico que las inspira: María Pita.
Esta heroína gallega se llamaba probablemente Mayor Fernández Pita; la conocemos como María Pita pues este era el nombre de su madre (María Pita "la vieja", como aparece en algunos documentos) y, por aquel entonces, resultaba frecuente que los hijos fueran llamados con el nombre de los padres (Saavedra Vázquez 2001: 341; 2003: 24-25 y 29; 2011: 32-33).

María Pita habría nacido en A Coruña en torno a 1556 en una familia de orígenes modestos. Sus padres se habían casado en 1554 y regentaban una tienda en el barrio de la Pescadería, un negocio en el que, durante su primera juventud, trabajaría nuestra protagonista $(\mathrm{Ca}-$ baleiro Manzanedo 1990: 100; Saavedra Vázquez 2001: 341-342 y 353; 2003: 132; 2011: 33-38; Ares 2007: 61).

Alrededor de 1581 María Pita se casa por primera vez; el elegido es Juan Alonso de Rois, carnicero de A Coruña con el que tiene una hija. A los pocos años se queda viuda, de modo que, antes de julio de 1587, vuelve a contraer nupcias con otro carnicero, Gregorio de Rocamonde, pero este fallece poco después del enlace, como consecuencia del asedio que sufre la capital herculina en 1589 por los ingleses. Este acontecimiento cambia la vida de María Pita, no solo porque pierde a su marido, sino, sobre todo, porque en el transcurso del mismo ella realiza la gesta por la que hoy es más recordada; siendo así, resulta pertinente dedicar algunas líneas a este suceso memorable (Martínez Salazar 1889: 135-136; García Oro 1997: 24; Saavedra Vázquez 2001: 341-342; 2003 : 64; 2011: 33-36 y 41).

No es fácil determinar por qué los ingleses asediaron A Coruña en la primavera de 1589. Tomar represalias por la ayuda que había prestado la ciudad gallega a la Armada Invencible cuando esta hizo escala en ella, destruir las naves que habían sobrevivido a dicho conflicto (algunas de las cuales estaban fondeadas en esos momentos en el puerto brigantino, entre ellas el galeón San Juan) o abrirse paso hacia Lisboa con el objetivo de colocar en el trono de Portugal -anexionado por España en

57 La Correspondencia de España (27 de noviembre de 1866: p. 3). Disponible en: http://hemerotecadigital.bne.es/ issue.vm? id=0000079480\&search=\&lang=es [consulta: $12 / 05 / 2018$ ].

58 La Correspondencia de España (15 de mayo de 1867: p. 3). Disponible en: http://hemerotecadigital.bne.es/issue. $\mathrm{vm}$ ?id=0000084921\&search=\&lang=es [consulta: 12/05/2018].

59 Véase Robello y Vasconi 1867.

60 Sobre esta obra, véase Ferreras 1979.

61 Véase Palau-Dulcet 1965: 120. 
1580 - a don Antonio, prior de Crato y primo de Felipe II, a cambio de convertir el país luso en un protectorado de Inglaterra, se postulan como algunas de las posibles causas del asedio (Martínez Salazar 1889: 40; Saavedra Vázquez 1989: 78-83; 2011: 53-59; Ares 2007: 64; Gorrochategui Santos 2011: 21 y 64-71; Peña y Martínez Pinna 2016: 39-40 y 42).

Lo cierto es que el 4 de mayo de 1589 una flota inglesa de unos 180 barcos y 27667 hombres, capitaneados todos ellos por el famoso corsario inglés Francis Drake y el oficial John Norris, llega a A Coruña. Esa misma mañana un aviso procedente de Estaca de Bares y dos mensajeros del cabo Prior habían dado la voz de alarma. Tras hacer una misión de reconocimiento que acaba confirmando el peligro, se alerta desde la Torre de Hércules a las poblaciones cercanas, se envían peticiones de auxilio a distintas partes del Reino y se ordena la venida de las dos compañías de infantería presentes en Betanzos. Asimismo, dos galeras y el galeón San Juan, en acción conjunta con la compañía de Jerónimo de Monroy, logran impedir que los ingleses accedan a la zona portuaria. Los sitiadores terminan desembarcando al mediodía en la playa de Santa María de Oza; desde aquí, se dirigen hacia la ciudad. Por la noche, estando la población cobijada en la Pescadería, llegan los esperados refuerzos de Betanzos, a los que previamente se les había avisado de que intentasen acceder a A Coruña a través del camino de Bergantiños, teniendo en cuenta que los ingleses habían tomado las comunicaciones terrestres de la ciudad brigantina con Betanzos y Santiago (Saavedra Vázquez 1989: 80 y 88-89; 2003: 73; 2011: 65-67; Gorrochategui Santos 2011: 73-74 y 82-85; Peña y Martínez Pinna 2016: 42-43).

Al día siguiente, los ingleses se hacen con el control de la Pescadería. Igualmente, ocupan el convento de Santo Domingo, que, por su proximidad a la Puerta de Aires (Vigo Trasancos 2007: 164), constituía una posición estratégica desde la que poder atacar la muralla de la Ciudad Vieja, donde se encontraban refugiados los coruñeses; estos aguantan con valor, a pesar de las ofertas de rendición que les llegan del bando enemigo (Saavedra Vázquez 1989: 32 y 90-95; 2003: 77; 2011: 68-69; Ares 2007: 62; Gorrochategui Santos 2011: 97; Peña y Martínez Pinna 2016: 45).
Habida cuenta de la pretensión de los ingleses de penetrar en la Ciudad Vieja, se hacía necesario reforzar la muralla, un trabajo del que se encargan las mujeres; aunque estas ya habían participado en la contienda en tareas de avituallamiento -por ejemplo-, es ahora cuando comienza realmente el protagonismo femenino, que resultará decisivo para la victoria de la urbe gallega. Esto se pone de manifiesto el 14 de mayo, día en que los ingleses consiguen perforar la muralla mediante la detonación de una mina. Ante la amenaza que se cierne sobre ellos, hombres y mujeres no dudan en plantar cara a los sitiadores. Cuando los ánimos empiezan a decaer entre las filas españolas, María Pita, que había presenciado la muerte de su marido Gregorio de Rocamonde a manos de los enemigos, atraviesa con una pica a un oficial inglés; este hecho enardeció a los coruñeses, logrando la retirada de los invasores. Varios días después, el 19 de mayo, los ingleses parten definitivamente de A Coruña (Saavedra Vázquez 1989: 94-97; 2001: 344; 2003: 78-87; 2011: 70-71; García Oro 1997: 24; Ares 2007: 63-64; Gorrochategui Santos 2011: 109, 125 y 151-178; Peña y Martínez Pinna 2016: 46).

Meses después del asedio, María Pita se casa con el hidalgo y oficial de la marina Sancho de Arratia, unión de la que sobrevive una hija, de nombre Francisca; pero, al igual que sus dos anteriores maridos, Sancho de Arratia muere muy pronto, entre mayo y noviembre de 1592. En 1598, la ilustre coruñesa contrae nuevas nupcias con otro hidalgo, Gil de Figueroa, escudero de la Real Audiencia de Galicia. Este último matrimonio, del que nacen dos hijos varones (Juan y Francisco), es algo más duradero, pues Gil de Figueroa no muere hasta 1613 (Martínez Salazar 1889: 136; García Oro 1997: 24; Saavedra Vázquez 2001: 342-343; 2003: 87 y 105-169; 2011: 79, 82 y 98-115).

A lo que llevamos dicho hemos de sumar su largo periplo por los tribunales de justicia. Veintisiete $^{62}$ son los pleitos en los que se vio inmersa María Pita, entre los que se cuentan dieciséis querellas criminales -en nueve aparece como querellante y en siete como acusada. Este número tan elevado de causas judiciales responde, en parte, al proceso de criminalización al que fue sometida por la sociedad de su tiempo, una sociedad machista que veía con recelos que una mujer hiciera valer sus 
derechos con la firmeza con que lo hacía María Pita. Esto la llevó varias veces a la cárcel e, incluso, al destierro; pero, ante circunstancias tan adversas, ella no se amedrentó, sino que continuó batallando por defender sus intereses; así, llegó a ir hasta en dos ocasiones -en 1596 y en 1606- a Madrid para solicitar a la autoridad real una serie de mercedes. Las dos últimas décadas de su vida fueron medianamente tranquilas hasta su fallecimiento en Sigrás el 21 de febrero de 1643 (Martínez Salazar 1889: 151-154 y 183-191; García Oro 1997: 26-27; Saavedra Vázquez 2001: 347; 2003: 28 y 138272; 2011: 88-93, 139 y 146-147; Ares 2007: 64-65).

\section{La Defensa de La Coruña por la heroica María Pita (1784) y María Pita o la heroína de Galicia (1833)}

La comedia de Valladares y el drama de Robello no abordan la historia de María Pita -que acabamos de sintetizar en el apartado anterioren toda su extensión, algo que se explicaría por dos razones, fundamentalmente: primero, por la naturaleza dramática de ambas obras, sometidas, pues, a la duración limitada de toda representación teatral; y segundo, por la adscripción de ambos textos al teatro histórico, que exige al dramaturgo una labor de selección y reducción sobre la materia representable (Spang 1998: 36). Valladares y Robello deciden centrarse en un episodio concreto de la biografía de María Pita, aquel que más fama ha dado a la heroína gallega -como ya se apuntó más arriba-: su participación en la defensa de A Coruña durante el asedio inglés de 1589. Dicho episodio recibe un tratamiento distinto por parte de ambos autores, según veremos seguidamente.

La Defensa de La Coruña por la heroica María Pita, de Valladares de Sotomayor, arranca el día en que se celebra la boda entre el teniente Carlos Téllez y María Pita, hija de Leandro, el gobernador de A Coruña. Todo se encuentra preparado para el enlace cuando Leandro recibe una carta en la que se le alerta de la pretensión de los ingleses de atacar la ciudad brigantina. Reunido en consejo con otros cargos militares, el gobernador decide plantar cara a los ingleses, pese a la opinión contraria del alférez Basilio; este es partidario de entregar A Coruña a los enemigos, lo que le permitiría ganar tiempo para sus pretensiones amorosas con María Pita, después de que Leandro haya rechazado darle la mano de su hija. Viendo que todos estaban determinados a defender la ciudad, Basilio, en actitud hipócrita, asume en público la tarea de evitar el desembarco de la flota inglesa, una misión que, como era de esperar, no lleva a término. Los sitiadores desembarcan en el puerto y se enfrentan al pueblo coruñés, que se ve obligado a retirarse. En el segundo enfrentamiento que se produce contra los invasores, y en el que participan las mujeres, María Pita es hecha prisionera. En ese mismo enfrentamiento, Wilson, el comandante de los ingleses, cae en manos de Basilio, que aprovecha este triunfo en su propio beneficio: proyecta conceder A Coruña a Wilson a cambio de que este le ayude en sus cuitas amorosas, fingiendo la muerte de María Pita. El plan se desarrolla del siguiente modo: Basilio se presenta ante Leandro en compañía de Wilson; tras ponerle al corriente de todo lo sucedido (esto es, de su victoria sobre Wilson y de la captura de María Pita por los ingleses), Basilio informa al gobernador de A Coruña de la intención de Wilson de poner en libertad a su hija. Leandro se siente reconfortado ante tan buena noticia y pide a Carlos que sea él quien vaya a recoger a María Pita al navío inglés en el que esta se halla retenida. Una vez en el barco, los ingleses simulan un brindis con los españoles, en el transcurso del cual María Pita, a la que han dado de beber una confección para dormirla, cae desmayada en brazos de Carlos. Tomándola por muerta, el pueblo coloca el cuerpo de María Pita en un panteón, al que poco después acuden Wilson y Basilio; este último piensa sacar a la joven de aquel tétrico lugar una vez que los ingleses ocupen definitivamente A Coruña, con el fin de evitar posibles represalias por parte de sus conciudadanos. De este modo, el alférez deja todo dispuesto, ayudándose incluso del soborno, para que la ocupación inglesa se desarrolle con éxito. Wilson, consciente de que ya no necesita a Basilio (en quien, además, ve a un contrincante para lograr el amor de María Pita, de la que el inglés se ha prendado), decide matarlo en el propio panteón. Todo esto ocurre ante la atenta mirada de la heroína, que ya había vuelto en sí tras pasársele los efectos de la confección, por lo que quedaba enterada del plan trazado por sus enemigos. Cogiendo la espada en la que momentos antes había perecido Basilio, María Pita asesina a Wilson y sale del panteón con el firme propósito de preparar una ofensiva contra los sitiadores. Gracias a la rápida intervención de la joven, que moviliza a todos los coruñeses, los enemigos ven frustrados sus propósitos de invadir A Coruña. 
En María Pita o la heroína de Galicia, de Robello y Vasconi, el asedio inglés de A Coruña no se dramatiza ex ovo, como en la obra de Valladares, sino in medias res. El acto I comienza cuando los coruñeses, junto con algunos vecinos de Betanzos, se encuentran atrincherados en la Ciudad Vieja. El marqués de Cerralbo, gobernador de A Coruña, convoca al oidor Juan Arias y a Gregorio Rocamonde, esposo de María Pita, para pedirles consejo en tan difíciles momentos. Gregorio propone que pidan más refuerzos a través de algún emisario, un cometido que Juan Arias acepta llevar a cabo esa misma noche. Momentos después, el sargento Luis de León informa al gobernador de que los ingleses han tomado el convento de Santo Domingo, en cuya defensa ha resultado herido el capitán Manrique, prometido de Isabel, la hija del marqués. Con objeto de recuperar el convento, Cerralbo lanza una ofensiva contra los ingleses, en la que también toman parte las mujeres, por iniciativa de María Pita. Desgraciadamente, en el transcurso de esa ofensiva, Gregorio Rocamonde pierde la vida. Por su parte, Drake se entrevista con Cerralbo para intentar lograr la rendición definitiva de la capital herculina. María Pita, que se halla presente en dicha entrevista, advierte al corsario inglés que primero daría la vida que entregarle la ciudad. Drake parte decidido a dar el golpe final pero nada podrá hacer ante la tenacidad y el arrojo de sus contrarios: cuando Norris, otro de los comandantes ingleses, se dispone a entrar en la Ciudad Vieja con la bandera británica, María Pita lo traspasa con su lanza y le arrebata la insignia, lo que determina la victoria definitiva de los españoles.

A la luz de estas sinopsis argumentales, la primera diferencia que salta a la vista entre ambos textos es que María Pita o la heroína de Galicia tiene una mayor historicidad; de hecho, en el manuscrito de la Biblioteca Nacional de España, esta obra aparece subtitulada como "drama historial en dos actos" (fol. 1r; la cursiva es mía); además, el texto viene precedido por una indicación que hace hincapié en que "el hecho es historial" (fol. 1v). Esto queda confirmado a través del análisis de la acción dramática: la llegada a A Coruña de refuerzos provenientes de Betanzos, la toma del convento de Santo Domingo por los ingleses o las ofertas de rendición de estos últimos a los defensores de la ciudad son algunos de los hechos que tuvieron lugar en la capital herculina durante el ataque inglés de 1589 y que Robello recoge en su drama con bastante fidelidad; por ejemplo, en relación a los refuerzos de Betanzos, sabemos que estos consistieron en las dos compañías de infantería de los capitanes Juan de Monsalve y Pedro Ponce, que pudieron entrar en A Coruña gracias a la pericia del capitán Juan Varela, un militar veterano que había servido en Flandes. Ambas compañías se habían abierto paso entre los ingleses, logrando acceder a la ciudad desde la playa de Orzán (Saavedra Vázquez 1989: 90; Gorrochategui Santos 2011: 86-87). Veamos ahora el grado de exactitud con que este suceso histórico es referido en el drama de Robello, por boca de Lobo:

LOBO. Tan solo han venido a favorecernos con su gente los capitanes don Juan de Monsalve y don Juan Pedro Ponce, que estaban en Betanzos, a los que se juntó el capitán Varela, natural de esta ciudad, que estaba en su aldea de recreo; los tres reunidos con su gente han entrado de socorro en la ciudad, que, aunque el enemigo tiene tomados los pasos, el capitán Varela, como práctico en este terreno y valiente militar, los siguió con tal ardid que mató a muchos; y desviándose de un cuerpo de guardia que los comenzó a cargar, pasaron por entre todos y la mar que llaman Orzán, logrando entrar en la ciudad. (fols. 12r-13r)

Pero no solo eso; gran parte de los personajes que intervienen en María Pita o la heroína de Galicia están tomados realmente de la historia; es el caso de Francis Drake y John Norris, Gregorio Rocamonde, Juan Arias, Luis de León y el marqués de Cerralbo -además de María Pita, claro está.

Sobre los dos primeros (Drake y Norris), ya señalamos anteriormente que fueron los cabecillas de los ingleses y como tales aparecen en el drama de Robello. El marino Francis Drake (1540-1596), al igual que su maestro John Hawkins, destacó por sus reiterados ataques contra las posesiones del imperio español, convirtiéndose en uno de los corsarios más temidos de su tiempo (Saavedra Vázquez 1989: 20 y 108-109). Por su parte, el soldado John Norris (¿1547?-1597) es conocido por la crueldad que empleó en algunas de sus campañas militares, como la masacre producida en julio de 1575 en la isla de Rathlin (Irlanda del Norte), una empresa en la que también tomó parte Drake pero de la que suele considerarse a Norris como el principal responsable. De hecho, esta personalidad sanguinaria de Norris queda bien plasmada en la obra que aquí comentamos, como es posible apreciar en el siguiente parlamento: 
NORRIS. Seguramente que el triunfar de esta población nos cuesta más que otras provincias enteras. Yo os aseguro, Jamson, que si como soy el segundo jefe del ejército, residiese en mí todo el mando, no había de quedar piedra con piedra de esa población; que este era el modo que aprendiesen otras a respetar las armas inglesas. Con los contrarios poca conmiseración o, por mejor decir, ninguna. ¿No sois de mi opinión, Jamson?

JAMSON. No lo dudéis y también creo que nuestro jefe superior sea de la misma.

NORRIS. Sí, pero en siendo valiente el enemigo, se compadece de él. (fol. 52r-v)

En cuanto a los personajes históricos que combatieron en las filas españolas, hemos mencionado a Gregorio Rocamonde, Luis de León, Juan Arias y el marqués de Cerralbo.

De Gregorio Rocamonde, se sabe que estuvo casado con María Pita y que perdió la vida durante el asedio -como antes se dijo. Respecto a Luis de León y Juan Arias, el primero fue sargento mayor del Tercio de Sicilia y, por su participación en la defensa de la ciudad, obtuvo 200 ducados de renta (Saavedra Vázquez 1989: 105; Gorrochategui Santos 2011: 80-81); el segundo (Juan Arias), al que se le presenta en el drama como "oidor de la Real Audiencia" (fol. 1v), se trata posiblemente de Francisco Arias Maldonado (1545-1625), un salmantino licenciado en Leyes que, en 1589 , se encontraba en A Coruña ejerciendo un cargo de responsabilidad en la Real Audiencia de Galicia $^{63}$; esta institución, que había fijado su sede en la capital brigantina en 1563 por decisión de Felipe II, consistía en un tribunal real cuya presidencia recaía en el gobernador y capitán general del Reino, que, por aquel entonces, era Juan Pacheco Ossorio, II marqués de Cerralbo ${ }^{64}$ y cuarto personaje al que hemos aludido más arriba (Navascues-Benlloch 1996: 14; Saavedra Vázquez 2011: 15, 19-20, 52 y 143$)$.

De todo lo dicho tampoco debe desprenderse que la obra de Robello se ajuste estrictamente a la verdad histórica; antes bien, en ella localizamos alguna que otra inexactitud; por ejemplo, en el acto I (escena $1^{\mathrm{a}}$ ), Lobo afirma que Gregorio Rocamonde trabaja como hornero ("que es un honrado hornero de esta ciudad" [fol. $12 \mathrm{r}$ ]), mientras que su verdadero oficio era carnicero - como ya se vio más arriba-. Más adelante encontramos otro ejemplo: María Pita confiesa al marqués de Cerralbo que ella está al cuidado de su madre y de sus dos hijos ("y en el que cuidar a mi anciana madre y a mis dos hijos" [fol. 44r]), lo que no se corresponde con la historia, dado que, en 1589, la heroína únicamente tenía una hija, la nacida de su primer matrimonio con Juan Alonso de Rois; tampoco es cierto que, por aquel entonces, María Pita cuidara de su madre, pues esta última había fallecido en 1583 (Saavedra Vázquez 2011: 38-39). Ahora bien, a nuestro entender, dichas inexactitudes no han de enjuiciarse de forma severa, en primer lugar, porque estas resultan insignificantes en el conjunto de la obra y, en segundo lugar, porque estamos ante un texto literario de carácter histórico y no ante un texto historiográfico $\mathrm{y}$, en consecuencia, no se reproducen servilmente los acontecimientos sino que se recrean (Spang 1998: 28 y 36). No podemos olvidar que Robello es escritor y, como tal, no renuncia a su derecho a la imaginación, de ahí que, por ejemplo, cree una trama amorosa entre Isabel, la hija del marqués de Cerralbo, y el capitán Manrique. No obstante, hay que decir que dicha trama es secundaria y que su existencia no desvirtúa la materia histórica que se está dramatizando y que ocupa el primer plano. No ocurre así en la comedia de Valladares de Sotomayor, donde la trama amorosa que se crea monopoliza toda la obra y altera sustancialmente el episodio histórico del asedio de 1589; Valladares fusiona dicho episodio con un triángulo amoroso (inventado) cuyos vértices son María Pita, Carlos Téllez y el alférez Basilio; el propósito de este último personaje de conseguir el amor de la heroína a cualquier precio es lo que marca, en la comedia, el transcurso del cerco inglés de A Coruña: primero, el alférez consiente el desembarco de los ingleses $\mathrm{y}$, posteriormente, traza un plan para hacer pasar por muerta a María Pita y entregar la capital herculina en manos de los sitiadores, hechos estos que no son históricos. Tampoco parecen serlo los personajes que aparecen en la comedia, a excepción de María Pita.

63 Información facilitada por la Real Academia de la Historia. Disponible en: http://dbe.rah.es/biografias/61417/francisco-arias-maldonado [consulta: 17/05/2018].

64 Sobre el marqués de Cerralbo, véase Fernández Caamaño 2014. 
El carácter inventivo de Valladares frente a la mayor fidelidad histórica de Robello se explicaría, a nuestro modo de ver, por el hecho de que ambos autores construyen sus respectivos textos bajo fórmulas dramáticas distintas. La Defensa de La Coruña por la heroica María Pita pertenecería al grupo de las llamadas 'comedias heroicas', obras que responden a un concepto de dramaturgia heredado del Barroco, en el que el dramaturgo, generalmente, trataba con bastante libertad las fuentes históricas; el respeto a estas fuentes quedaba normalmente supeditado al afán prioritario de presentar al público una obra lo más entretenida posible. En el siglo XVIII, esta fórmula dramática no solo no desaparece, sino que, beneficiándose de los avances escenográficos que trae consigo la nueva centuria, aumenta su atractivo sobre los espectadores. Célebres dramaturgos dieciochescos escribieron comedias heroicas, para las que, en muchos casos, tomaron como protagonistas a mujeres, en línea con lo que anteriormente habían hecho los autores barro$\cos ^{65}$; entre los ejemplos que podrían mencionarse al respecto, además de la Defensa de La Coruña por la heroica María Pita (1784), se encontrarían A España dieron blasón las Asturias y León y triunfos de D. Pelayo (1778) de José Concha, La defensa de Barcelona por la más fuerte amazona (1788) de Fermín del Rey, El sitio de Calés (1790) y La Judit castellana (1791) de Francisco Luciano Comella, o Aragón restaurado por el valor de sus hijos (1790) y La más heroica espartana (1800) de Gaspar Zavala y Zamora (Fernández Cabezón 2003: 118-119).

En los primeros decenios del siglo XIX, los importantes acontecimientos ocurridos en España (como la Guerra de la Independencia o la crisis de las colonias españolas en América) suscitan un renovado interés por la historia, por la reflexión y el análisis del pasado nacional (Canellas López 1989: 256). En este contexto, fructifica una nueva fórmula teatral, el drama histórico, que, frente a las comedias heroicas, suele caracterizarse por una mayor fidelidad a la historia; así lo sugiere uno de sus más destacados cultivadores y teóricos, Francisco Martínez de la Rosa (1787-1862), en sus
"Apuntes sobre el drama histórico" $" 66$, contenidos en el tomo V de la edición de sus Obras literarias, tomo que sale de la imprenta parisina de Didot en 1830 (Coca Ramírez 2000: 116):

Limitándonos ahora a nuestro propósito, cuando poco después de Juan de la Cueva tomó tan rápido vuelo el teatro español, gracias al impulso de Lope de Vega, y cuando Calderón y otros autores célebres lo levantaron luego a su mayor altura, creció a la par la afición a las composiciones históricas, concurriendo a ello de consuno el gusto de la nación y la inclinación de los poetas. Según hemos insinuado en otro lugar, los dramáticos españoles tenían, en general, más genio que cordura y más talento que instrucción; así es que se sentían más inclinados a presentar en las tablas hechos que despertasen la curiosidad, a encadenarlos con sagaz artificio y a arrastrar en su rápido curso el ánimo de los espectadores (...) Empero las mismas causas que estimulaban a nuestros dramáticos a dedicarse de buen grado a composiciones históricas, les impedían aventajarse mucho en ellas. No hay hecho grave, por sencillo que sea, que no exija, para comprenderle a fondo y ponerle de bulto, largo estudio y profunda meditación; y nuestros poetas, lejos de sujetarse a tan penoso trabajo, preferían lucir su fácil inventiva y dejar campear su lozano ingenio (...) Cabalmente, cuando se trata de argumentos históricos, la primera cualidad es la verdad de la imitación, pues, aunque no se exija, y antes bien sea grave falta, reducirse a una copia servil, nunca debe perderse de vista la índole de semejantes composiciones. (Martínez de la Rosa 1830: 367-369)

Esta preocupación del crítico granadino por la fidelidad -si bien no servil- a la historia también aparece en el 'avant-propos' que antepone a su obra Aben Humeya, considerada por Caldera y Calderone (1988: 451) como el primer drama histórico español y publicada en versión bilingüe (francés-español) en ese mismo tomo $\mathrm{V}$ antes aludido:

Ayant conçu cette idée toute simple du drame historique, il s'agissait de remplir de mon mieux les deux conditions essentielles qui semblent en dériver: il fallait tracer le tableau avec la plus grande fidélité possible, sans rechercher néanmoins cette exactitude scrupuleuse qu'on exige dans une chronique; mais en s'efforçant

65 Véase, por ejemplo, Ziomek 1983.

66 Distintos críticos han comentado estos “Apuntes...”; véanse Coca Ramírez 1998; 2000; González de Garay Fernández 1983: 226-227; Rodríguez Sánchez de León 2003: 1876-1877. Asimismo, se puede encontrar una transcripción de dichos “Apuntes...” en Navas-Ruiz 1971. 
de graver sur l'ouvrage, comme sur une médaille, le cachet de l'époque et du pays. Une fois l'esquisse du tableau faite, on devait tâcher d'y encadrer en quelque sorte une tragédie; car je suis intimement convaincu (et si c'est une erreur, elle est bien excusable) que jamais le drame historique ne réussira au théâtre, que lorsqu'il parviendra à satisfaire en même temps la raison et le coeur, par le reflet fidèle d'un grand événement, ainsi que par la lutte animée des passions. (Martínez de la Rosa 1830: v-vi)

Como vemos, además de la historicidad, otra de las condiciones que deben cumplir los dramas históricos consiste en presentar al espectador pasiones animadas. Ambas condiciones obedecen respectivamente al doble propósito de este tipo de obras, esto es, "satisfaire en même temps la raison et le coeur", en otras palabras, transmitir al público una enseñanza $y$, al mismo tiempo, reportarle placer (Coca Ramírez 1998: 103); a este asunto se refiere de manera más explícita Martínez de la Rosa en sus citados "Apuntes...":

Basta, pues, que el drama histórico posea la condición esencial de reunir la utilidad y el deleite, para que deba hallar en el teatro acogida y aceptación; y cierto que pocas composiciones habrá que puedan ser de suyo tan instructivas y ofrecer al ánimo un desahogo tan apacible (...) Por eso me parece necesario tratar ante todas cosas de conmover el corazón, presentando al vivo sentimientos naturales y lucha de pasiones; que ese es el mejor medio, si es que no el único, de embargar la atención, de excitar interés y de ganar como por fuerza el ánimo de los espectadores. Así pudiera, hasta cierto punto, reunirse en esta clase de dramas la utilidad de la historia y el encanto de la tragedia; no será tal vez empresa fácil, pero ese debiera ser por lo menos el punto de mira. (Martínez de la Rosa 1830: 366-370)

No sabemos con seguridad si Francisco Robello llegó a conocer estas ideas de Martínez de la Rosa antes de componer María Pita o la heroína de Galicia (una posibilidad que no se puede descartar si se atiende a la cronología: las consideraciones del autor granadino se publicaron en 1830 -como hemos indicado arriba- y el drama que aquí estudiamos se habría escrito tres años después). Lo que sí podemos afirmar es que la obra de Robello parece responder al canon de drama histórico descrito por Martínez de la Rosa: María Pita o la heroina de Galicia muestra, por un lado, una actitud de respeto y fidelidad, aunque no de servilismo, hacia la verdad histórica -ya se vio anteriormente $-\mathrm{y}$, por otro, plasma con gran maestría y viveza pasiones y sentimientos humanos; un ejemplo de esto último lo encontramos en Isabel, que vive en un continuo desasosiego interior al ver peligrar la vida de su padre, el marqués de Cerralbo, y de su amado, el capitán Manrique, a causa del asedio inglés:

ISABEL. ¡Desventurada! ¿Qué acaso tan imprevisto como funesto ha traído a estos hombres a nuestras costas para causar mi desolación, mi eterna desdicha? En el momento que se preparaba mi enlace, al que asentía gustoso mi amado padre, con el hombre más amable del mundo...; en el instante mismo de mi felicidad..., se ve amenazada esta población por tropas numerosas. Mi padre, mi amante, también corren a su defensa como valientes y militares y no solo se difiere mi himeneo, sino que, ¡oh, Dios!, estos dos objetos idolatrados de mi alma están expuestos a perecer. (fols. $6 \mathrm{v}-7 \mathrm{r}$ )

La angustia de la joven se intensifica aún más cuando se ve obligada a dejar marchar herido al capitán Manrique; este ha recibido una lesión en un brazo luchando contra los ingleses, pero, en vez de recuperarse, opta por seguir defendiendo A Coruña de los sitiadores:

ISABEL. Conozco con harto sentimiento tus razones, pero... Suena un clarín y dos cañonazos. ¡Oh, Dios, ya llegó el momento!

MANRIQUE. Sí, esta es la señal de alarma. Corro, no puedo detenerme. Saca el estoque.

ISABEL. ¡Manrique, Manrique, conserva tu existencia!

MANRIQUE. Adiós, Isabel. Voy al combate. Muy pronto vendré a poner a tus pies mi victoria. Vase.

ISABEL. ¡Justo Dios, salvad su vida y la de mi padre! Si ha de perecer uno de los dos, haced que en cambio muera yo primero. ¡Proteged su existencia, gran Dios! Vase. (fol. 21r)

Aunque podrían ponerse muchos más ejemplos, creemos que los fragmentos reproducidos son suficientes para comprobar cómo Francisco Robello presenta "al vivo sentimientos naturales y lucha de pasiones" -en palabras de Martínez de la Rosa-, ayudándose de distintos recursos, como el empleo de invocaciones y de la interjección $o h$. A este respecto, cabe hablar también del estilo de María Pita o la heroina de Galicia; dicho estilo se distancia de la grandilocuencia característica de la tragedia, así como de la llaneza o sencillez propias de la comedia; de hecho, ni siquiera los personajes 
construidos sobre el tipo ${ }^{67}$ del criado, como Lobo, hablan de forma grosera o distorsionada (es decir, con imperfecciones lingüísticas), como ocurre normalmente en otras obras (por ejemplo, en la de Valladares). De este modo, el drama de Robello se ajustaría a las pautas estilísticas que Martínez de la Rosa aconsejaba para el drama histórico:

En general, el drama histórico no requiere quizá tanta elevación como la tragedia; admite con menos dificultad personas de condición más llana, desciende con gusto a pormenores más leves, se acerca más a la vida común; y el estilo debe irse plegando suavemente a tan varias formas, remontándose sin arrogancia y abatiendo el vuelo sin rasar la tierra (...) (Martínez de la Rosa 1830: 372)

Por último, otro de los rasgos del drama histórico sugerido por Martínez de la Rosa consiste en el acatamiento de la regla de las tres unidades dramáticas. El texto de Robello cumple la unidad de acción, en la medida en que las distintas partes que integran la acción dramática contribuyen todas a un mismo fin, de carácter didáctico-ideológico: la defensa de la libertad, representada por María Pita, contra todo poder tirano, encarnado en los ingleses.

Algo más transgresor se muestra Robello en cuanto a la unidad de lugar ${ }^{68}$. En sus "Apuntes sobre el drama histórico", Martínez de la Rosa insinúa modificar la escena fundamentalmente en los entreactos ("Cada acto, como parte distinta y separada, puede muy bien suponerse acaecido en diverso lugar, sobre todo si no están entre sí muy distantes"; 1830: 371) y así lo hace Robello. No obstante, este también cambia la escena a veces durante el transcurso de un mismo acto, si bien este tipo de cambios no se producen en exceso ni de forma arbitraria o caprichosa, sino que vienen justificados por el devenir de la acción, asunto al que igualmente se refiere el escritor granadino:

Muy menguado concepto tendrá de su arte el poeta que sacrifique una situación hermosísima o que incurra en un absurdo manifiesto, por no mudar una que otra vez el lugar de la escena; pero el que haga peregrinar a sus personajes sin tino ni mesura, corre riesgo de recordar frecuentemente a los espectadores lo que con tanto afán debe procurarse que olviden. (Martínez de la Rosa 1830: 371; la cursiva es mía)
La unidad de tiempo se observa más claramente. Según nuestros cálculos, la acción dramatizada en María Pita o la heroína de Galicia abarcaría aproximadamente dos días en la realidad: en el primer día (acto I), se produce la toma del convento de Santo Domingo por los ingleses y la consiguiente ofensiva que lanzan los españoles para recuperar esa posición; al día siguiente (acto II), tiene lugar el enfrentamiento definitivo entre los defensores y los ingleses, con la posterior derrota de estos últimos. Robello aprovecha el entreacto, en cuanto período en el que se suspende la ilusión teatral, para hacer avanzar el tiempo representado: el acto I concluye con el fallecimiento de Gregorio Rocamonde en presencia de María Pita y en el acto II (escena $2^{a}$ ) la heroína afirma ante el marqués de Cerralbo que "van a cumplirse veinte y cuatro horas que sucumbió" su marido (fol. 41r). En este punto, Robello vuelve a coincidir con Martínez de la Rosa, quien aconsejaba en sus "Apuntes..." servirse de los entreactos para conseguir la unidad de tiempo:

Tampoco se debe regatear sobre el tiempo que se supone dura la acción; basta que lo que pasa a la vista de los espectadores pueda haber sucedido realmente en el mismo espacio, poco más o menos, y que lo restante del tiempo que ha tomado el poeta lo haya distribuido con tal sagacidad, especialmente entre los actos, que el espectador no se aperciba de ello o lo tolere de buen grado. (Martínez de la Rosa 1830: 371)

A partir de nuestro análisis, consideramos justificada la catalogación de María Pita o la heroína de Galicia como drama histórico, puesto que, en líneas generales, la obra de Robello (subtitulada en el manuscrito como "drama historial" [fol. 1r] -conviene no olvidarlo-) sigue muy de cerca las pautas teóricas marcadas por Martínez de la Rosa.

Una vez realizado este excurso, necesario para comprender la mayor historicidad del texto de Robello frente al de Valladares, proseguimos con nuestro estudio.

Además de la fidelidad a la verdad histórica, otro de los aspectos en los que Robello se aparta de Valladares es la ideología, como se desprende, por ejemplo, de sus respectivas concepciones del poder político y de la mujer. 
Las ideas que Robello y Vasconi manifiesta en María Pita... son de carácter progresista, en consonancia con la nueva conciencia política que se había introducido en España a partir de la Constitución de 1812; en consecuencia, la imagen que el dramaturgo traslada de la política en su drama es la de una actividad hasta cierto punto democrática, en la medida en que no está reservada exclusivamente a las clases privilegiadas; esto queda patente nada más comenzar el acto I, cuando el marqués de Cerralbo, a la hora de decidir su estrategia de actuación frente al ataque inglés, no solo pide consejo a Juan Arias, alguien perteneciente a la élite del poder por su condición de oidor de la Real Audiencia de Galicia, sino también a Gregorio Rocamonde, el marido de María Pita, un hombre humilde, un simple hornero -carnicero en la realidad, como se apuntó más arriba.

Respecto a la visión que Robello ofrece de la mujer a través del personaje de María Pita, esta resulta más positiva que la que veremos en Valladares. El comportamiento de la heroína durante toda la obra corresponde al que de ella nos ha transmitido la historia, es decir, el de una luchadora incansable en favor de su libertad y la de su pueblo; de ello nos da cuenta el capitán Manrique:

MANRIQUE. Confiad, señor, todavía. En la pasada noche ha conseguido el oidor Arias, con una chalupa y sin ser visto del enemigo, desembarcar en la orilla del Mera (...) La tropa y los paisanos, a vista de los mayores peligros, están más y más entusiasmados y es admirable ver esa heroica María, a quien desgraciadamente ha muerto el enemigo a su valiente marido en el último choque, alentar al combate a sus compatricios; no descansa un momento: los instantes que dejamos el combate, los emplea en fabricar cartuchos, en socorrer a los heridos; ella misma ha dado sepultura a su desgraciado esposo y sobre su tumba ha jurado vengar su muerte. (fol. 35r-v)

Nos parece importante señalar que Robello no intenta justificar la heroicidad del personaje de María Pita confiriéndole rasgos caracterológicos tradicionalmente considerados masculinos o varoniles -como sí hace Valladares, según veremos-; es más, en la obra de Robello, María Pita defiende su condición de mujer y no ve en dicha condición ningún obstáculo para luchar de igual a igual con un hombre, como se deduce de las desafiantes palabras que dirige a Drake:

MARÍA PITA. Qué, ¿juzgáis del pueblo coruñés que podrá aceptar vuestras propuestas? ¡Ah, cómo os engañáis! ¿El paisanaje cede, habéis dicho? ¡Sí, cede en la tumba cuando se trata de esclavizarle e imponerle leyes una nación extraña! ¿Sabéis cómo cede el paisanaje gallego?; como ha cedido mi esposo, ¡atravesado su pecho por una de vuestras lanzas! ¡Él ha expirado en mis brazos, pero yo me he encargado de vengarle y sabré cumplirlo!; aunque la guarnición, aunque los paisanos sucumbiesen, que están lejos de hacerlo, iyo sola me pondría en una de las puertas de la ciudad y no entraríais en ella sin primero hollar mi cadáver!; ipero antes os costaría bien caro este triunfo! (fol. 48r-v)

Además de lo dicho, hemos de comentar los orígenes humildes de María Pita. A diferencia de lo que observaremos en Valladares de Sotomayor, Robello no aristocratiza a nuestra protagonista, sino que mantiene su perfil (histórico, por otra parte) de mujer modesta, del pueblo, lo que da pie al dramaturgo a llevar a cabo una reivindicación -acorde a su ideología progresista- de la igualdad moral entre las clases sociales; como portavoz de esa conciencia igualitaria utiliza al personaje de Manrique:

MANRIQUE. Verdaderamente singular; yo mismo envidio su valor. ¿Será posible que una mujer de lo ínfimo de la plebe abrigue en su pecho tan heroicos sentimientos? Esto prueba que las virtudes no conocen clases, que pueden poseerlas en el más alto grado lo mismo el noble que el plebeyo y que es todavía más recomendable su posesión en una persona de principios vulgares, como así mismo el vicio es más detestable en individuos de alta categoría. (fol. 40r)

Más adelante, Manrique vuelve sobre la misma idea, refiriéndose nuevamente a María Pita: " ¡Cuántas personas de alta clase cambiarían vuestra suerte por la suya, a trueque de poseer prendas tan recomendables!" (fol. 43r-v). Como vemos, Robello da entrada en su drama a la reivindicación social, algo que no resulta extraño en el teatro español decimonónico (Gies 1996: 3, 58 y 193). El que nuestro autor haya elegido la historia de María Pita como argumento para su obra no nos parece inocente, antes bien, constituiría "un acto de complicidad con el presente" (Ruiz Ramón 1989: 385), una expresión de su compromiso con el moderno sistema político que había empezado a gestarse en nuestro país a raíz de la experiencia de las Cortes de Cádiz. La historia de María Pita proporcionaba a Robello un material idóneo para hacer una apología de ese ideario progresista, una defensa de la libertad contra la represión, de la que él mismo había sido víctima durante el reinado de Fernando VII -como ya vimos al tratar su biografía. 
Pasando ahora a la Defensa de La Coruña por la heroica María Pita, esta comedia habría sido compuesta casi medio siglo antes que el drama de Robello (siempre que tomemos la fecha de la representación de la obra [esto es, el año 1784$]^{69}$ como la misma de su redacción), por lo que pertenecería al Antiguo Régimen, lo que se traduce en una ideología más tradicional. Para nuestro análisis, nos detendremos en los dos mismos aspectos estudiados en relación a María Pita o la heroína de Galicia: la concepción del poder político y la consideración de la mujer, en este orden.

En el acto I de la comedia, Leandro (personaje que, en esta obra, desempeña las funciones del marqués de Cerralbo -recordemos-), después de ser informado de la intención de los ingleses de invadir A Coruña, convoca un consejo para deliberar sobre este asunto. En dicho consejo únicamente son llamados a participar altos cargos militares (entre ellos, el teniente Carlos Téllez y el sargento mayor Delgado), de lo que se deduce que Valladares entiende el ejercicio del poder político como algo cerrado, elitista, reservado únicamente a las clases privilegiadas. Por otro lado, Leandro representa al gobernante paternalista característico del Antiguo Régimen; de hecho, en alguna ocasión, él se refiere a sí mismo con el término padre:

LEANDRO Vengan todos, pues un padre más que un gobernador tienen siempre en mí, y en este día haré cuanto me pidiesen.

$\mathrm{Ve}(\mathrm{s})$, Bernardo, y haz que todo pronto esté para el banquete. $(\text { fol. } 2 \mathrm{v})^{70}$

Lo mismo hacen con él otros personajes, como Caimán:

CAIMÁN Señor gubernador nuestro, vusiría mos dispense que pus hoy a la señora
María Pita, su hija, quiere

unirla en el matrimoño al teniente Carlos Téllez, nuestro paisano, vengamos los serranos a ofrecelle la voluntad tan sincilla, que le mos tenido siempre; pus aunque es nuestro mandante, como a un padre se le quiere.

(fol. 10v; la cursiva es mía) ${ }^{71}$

En lo que se refiere a la consideración de la mu$\mathrm{jer}^{72}$ en la comedia de Valladares, cabría empezar recordando que, en la sociedad del Antiguo Régimen, los papeles asignados a cada uno de los sexos estaban perfectamente delimitados. Al hombre le correspondía un carácter activo, enérgico, necesario para desenvolverse en la esfera pública; por contra, a la mujer se la identificaba con la pasividad y, en consecuencia, con el ámbito privado-doméstico. Esto explica que, en muchas de las obras dramáticas del Antiguo Régimen en las que aparece un personaje femenino protagonizando acciones ajenas a ese ámbito (privado-doméstico), el dramaturgo en cuestión le dote de un carácter varonil, que llega a materializarse incluso, a veces, en la propia vestimenta; en relación a esto último, son numerosos los casos de mujeres disfrazadas de hombre que nos ofrece el teatro barroco ${ }^{73} \mathrm{e}$, incluso, el del siglo XVIII" . "De este modo se refuerza su imagen [la de la mujer] como un ser inferior que sólo puede aspirar a la perfección imitando a los hombres" (Saavedra Vázquez 2001: 345).

La Defensa de La Coruña por la heroica María Pita no constituye ninguna excepción al respecto, desde el momento en que Valladares confiere a la heroína gallega rasgos varoniles siempre según los esquemas mentales de aquel momento-, lo que se pone de manifiesto, en el acto I de la comedia, por contraste con Gertrudis, prima de María Pita y encarnación del

69 Véase Andioc y Coulon 1996: 386 y 684.

70 De la Defensa de La Coruña por la heroica María Pita existen, hasta donde sabemos, cuatro manuscritos, cuya localización pasamos a indicar: Biblioteca de la Universidad de Sevilla, A 250/114(2), disponible en: https://archive.org/details/A2501142 [consulta: 12/04/2018]; Biblioteca Histórica Municipal de Madrid, Tea 1-106-19, A; Tea 1-106-19, B; Tea 1-106-19, C. Para las citas textuales, emplearemos el manuscrito Tea 1-106-19, B, que es el que contiene las licencias de aprobación firmadas. Respecto a los criterios de transcripción, ya se especificaron en una nota anterior.

71 Tanto en este parlamento como en los que puedan salir en adelante, conservaremos las deformaciones lingüísticas con las que el dramaturgo ha caracterizado a personajes que, como Caimán, se han construido sobre el tipo del criado.

72 Sobre este asunto, véase Valladares de Sotomayor 1766.

73 Véanse, por ejemplo, Bravo-Villasante 1988; González González 1995: 61-69; Jauralde Pou 1998; Ferrer Valls 2003; González 2004.

74 Véase Fernández Cabezón 2003: 131-133. 
ideal femenino de la época. Pondremos dos ejemplos de este contraste.

En primer lugar, Gertrudis y María Pita distan en sus preferencias amorosas; mientras que la primera prefiere hombres cariñosos y apuestos, la segunda valora, ante todo, la destreza en la guerra:

\begin{tabular}{cl} 
MARÍA PITA & $\begin{array}{l}\text { Parece que con Ruperto } \\
\text { a solas, prima, te entiendes. }\end{array}$ \\
GERTRUDIS & $\begin{array}{l}\text { Pero dime, ¿no es galán } \\
\text { y bello? }\end{array}$ \\
MARÍA PITA & \multicolumn{1}{c}{ Sí, pero debes } \\
& $\begin{array}{l}\text { amarle más si en la guerra } \\
\text { es esforzado y valiente. }\end{array}$ \\
GERTRUDIS & $\begin{array}{l}\text { Solo a los hombres guerreros } \\
\text { y de valor, prima, quieres, } \\
\text { pero no a los cariñosos; } \\
\text { y a la verdad no lo entiendes, } \\
\text { porque amor todo es dulzuras } \\
\text { y Marte todo reveses. (fol. 13r) }\end{array}$
\end{tabular}

Es más, en la conversación que posteriormente mantiene con su prometido, María Pita parece ponderar la guerra por encima del amor:

TODOs ¡Viva el rey! ¡Viva la patria! $¡ O$ morir o defendernos!

Vanse todos. María detiene a Carlos.

MARÍA PITA Escucha, Carlos.

CARLOS

Di pronto, porque aquello es lo primero.

MARÍA PITA Con esa sola expresión me encantas. Solo te advierto, sepas dar las cuchilladas tan fuertes y con tal peso, que de cada una a un inglés partas por medio del cuerpo; y mientras más mates, más sabrá estimarte mi afecto. ¡Oh, si yo fuera contigo, yo te enseñaría a hacerlo!

CARLOS Si la dicha acompañase a mi valor, ten por cierto sabré adquirirme el mayor lugar.

MARÍA PITA ¿Adónde?

CARLOS

MARÍA PITA En tu pecho. Ya le tienes; mas te encargo no guardes lugar, ni puesto si hay batalla. Métete en lo más vivo y sangriento de ella, porque adonde está el mayor peligro, entiendo que está la gloria mayor, ya triunfando o ya muriendo.

CARLOS Mi amor sabrá obedecerte.

MARÍA PITA ¿Tu amor? Tu valor y esfuerzo has de decir, que el amor para esos casos no es bueno. (fols. 21v-22v)

En segundo lugar, María Pita muestra su desagrado por los cosméticos y los vestidos, ya que, en su opinión, estos le coartan su carácter guerrero (Fernández Cabezón 2003: 125); a estas consideraciones replica Gertrudis, recordándole a su prima el papel que le corresponde a la mujer en aquella época. Merece la pena reproducir el extenso fragmento:

MARÍA PITA Como estáis, amado padre, enseñado $^{75}$ solo a verme con el traje que se adapta más a lo honesto y decente, porque por naturaleza soy opuesta a los afeites, que sabe la vanidad inspirar a otras mujeres, y las armas son las que me dan gusto solamente, hoy extrañáis este fausto que ya cansada me tiene; pero el día de mis bodas preciso es se diferencie de los demás, porque dicen que el más agradable es este de nuestra vida, y es fuerza honrarle y favorecerle, trayendo a cuestas las galas que pudieran ser arneses.

GERTRUDIS ¿Arneses, prima? Estos son para aquellos hombres fuertes que, en la guerra, hacen prodigios de valor; mas las mujeres, con la aguja, la almohadilla, prendernos los alfileres y gobernar nuestra casa, cumplimos nuestros deberes.

MARÍA PITA Pero es fuerza que envidiemos a los hombres, porque pueden con la espada en la campaña coronarse de laureles, que ni el tiempo ni la envidia los arranquen de sus sienes.

75 El adjetivo enseñado se utiliza aquí con el significado de 'acostumbrado', que contempla la Real Academia de la Lengua Española. Disponible en: http://dle.rae.es/?id=Fd99XQ5 [consulta: 22/06/2018]. 
LEANDRO ¡Qué bien, María, acreditas así que mi sangre tienes!

MARÍA PITA ¿Y de qué sirve, señor, que el labio solo esto exprese, si por mujer pierdo que con obras lo manifieste? ¿Qué gusto el mío sería si en la campaña me viese, repartiendo en los contrarios cuchilladas y reveses!

Para mí fuera aquel día el más delicioso; en este ejercicio me ocupara sin cesar. ¿Y que quisiese darme la naturaleza un espíritu tan fuerte, y errase con embotarle haciéndome mujer? Pese a mí y a ella también, pues esto a las dos nos ofende; a ella porque erró y a mí porque sujeta me tiene a no hallarme en las batallas, porque visto guardapieses.

(fols. 5r-6v)

Lo que subyace en el fondo de estos versos es, a nuestro juicio, la idea -antes esbozada- de que la mujer resulta incapaz de emprender grandes acciones, hechos heroicos, si no es bajo el ropaje varonil, o sea, si no asume la condición masculina. Vemos, pues, que con el comportamiento y las palabras de María Pita, Valladares de Sotomayor, lejos de cuestionar los roles de sexo propios de su tiempo, los refuerza en su comedia, al menos durante el acto I.

A esta mentalidad patriarcal característica del Antiguo Régimen responden también dos de las principales modificaciones que el dramaturgo opera sobre el personaje histórico de María Pita: la soltería y la pertenencia a una clase social elevada.

Respecto a lo primero, bien sabemos que, en la época en que los ingleses atacaron A Coruña, María Pita estaba casada por segunda vez. Aunque en Europa no era extraño que las mujeres contrajesen segundas nupcias (Saavedra Vázquez 2003: 64-66; 2011: 41), no es menos cierto que esta práctica era objeto de recelos y de críticas desde un punto de vista moral y social, una actitud de animadversión que venía de muy antiguo (Marcos Casquero 2001); es por ello quizá que Valladares renuncia a seguir en este punto la verdad histórica y presenta a María Pita como una mujer soltera, aunque por poco tiempo, pues está a punto de contraer matrimonio con el teniente Carlos; el dramaturgo, por boca de la heroína, deja claro que este será el primer y único hombre en la vida de María Pita:

CARLOS Que no me olvides.

MARÍA PITA

No temas;

tú has sido el hombre primero que he querido, pero cree serás también el postrero. (fol. 23v)

En relación a lo segundo (el rango social elevado), Valladares convierte a María Pita en la hija de un gobernador, cuando, en la realidad -como ya vimos-, los orígenes de la joven eran modestos. No obstante, lo que apuntamos no es exclusivo de la obra de Valladares, ya que también se da en otras comedias heroicas del siglo XVIII con protagonistas femeninas, quienes suelen ser reinas, princesas, condesas, etc. -aunque siempre haya excepciones ${ }^{76}$. Este hecho respondería a la asociación, tan característica del Antiguo Régimen, entre la idea de heroicidad y la de nobleza / sangre ilustre (no hay más que recordar las palabras de Leandro, anteriormente reproducidas: "¡Qué bien, María, acreditas / así que mi sangre tienes!" [fol. 6r]).

Parte de estos postulados ideológicos (reaccionarios) de Valladares quedan, si no superados del todo, al menos sí un poco arrinconados a partir del acto II de la comedia, donde el dramaturgo subraya la activa participación que tuvieron las mujeres -aparte de María Pita- en la defensa de A Coruña; lo que nos resulta más relevante es que estas mujeres no están dotadas de un carácter varonil -a diferencia de lo que ocurría con nuestra heroína- y, en algunos casos, dichas mujeres pertenecen además a clases sociales bajas. Encontramos un ejemplo en Gertrudis y su criada Nicasia; ambas han intervenido en la batalla librada contra los ingleses junto a la muralla de la ciudad, como se aprecia en el siguiente parlamento:

CAIMÁN Y mueso gobernador tenga también enfenita salú, y enfenitamente se celebren de este día el triunfo de La Coruña por la heroica María Pita. 
NICASIA Y por todas las mujeres que la hicimos compañía; porque por mí, en los ingleses hice tan buena partija de garrotazos, que al que uno daba, allí moría.

GERTRUDIS Sí, Nicasia; te has portado.

NICASIA Pus osté, señoría mía, no fue vana; daba tales cuchilladas, que maldita la que dejó de costar por lo menos una vida. (fol. 17v)

En Nicasia y en Gertrudis tenemos a dos personajes dramáticos femeninos a los que Valladares les atribuye acciones valerosas sin someterlos previamente a un proceso de masculinización que justifique ese comportamiento (valiente) en la mujer y sin adscribirlos -en el caso de Nicasia- a una clase social elevada. ¿No entraría esto en contradicción con la postura retrógrada que había adoptado el dramaturgo durante el acto I de su comedia? Ciertamente, Valladares de Sotomayor estaría cayendo en contradicciones, si bien estas se explicarían por el momento histórico que le tocó vivir, la segunda mitad del siglo XVIII y los primeros decenios del XIX, una etapa de cambio en la que se agudiza la crisis del Antiguo Régimen y en la que se empiezan a dar los primeros pasos para la sustitución de aquel sistema político por uno nuevo, más moderno; de ahí que el pensamiento de Valladares, en ocasiones, se muestre apegado a la tradición y, en otros casos, presente visos de modernidad. De este modo, se nos revela "como un escritor en debate constante entre lo viejo y lo nuevo, entre convención y reforma" (García Garrosa 1995: 142).

\section{Conclusiones}

La Defensa de La Coruña por la heroica María Pita, de Antonio Valladares de Sotomayor, y María Pita o la heroína de Galicia, de Francisco Robello y Vasconi, se acogen a fórmulas dramáticas diferentes, lo que justifica el distinto manejo que hacen de la verdad histórica. Asimismo, ambos textos son fieles productos de sus respectivas épocas, como se observa en el terreno ideológico.

Especial relevancia tiene en nuestro trabajo el drama de Robello, al ser una obra que ha permanecido durante todo este tiempo en el más absoluto de los olvidos, por lo que era necesario llamar la atención sobre ella.

En definitiva, con este artículo esperamos haber rendido homenaje a todas aquellas mujeres que, junto a María Pita, tomaron parte en la defensa de A Coruña aquel memorable año de 1589.

\section{Referencias bibliográficas}

Álvarez Barrientos, Joaquín (1992): "La figura del escritor en el siglo XVIII”, Cuadernos de Ilustración y Romanticismo 2, pp. 13-30, https://revistas.uca.es/index.php/cir/article/view/417/373 [consulta: 20/04/2018].

Andioc, René y Mireille Coulon (1996): Cartelera teatral madrileña del siglo XVIII (1708-1808). Toulouse: Presses Universitaires du Mirail.

Ares, María (2007): "María Pita: una gallega de armas tomar", Clío. Revista de Historia 63, pp. 60-65.

Armona y Murga, José Antonio (2007): Memorias cronológicas sobre el origen de la representación de comedias en España (año de 1785). Londres: Tamesis Books. Edición de Charles Davis.

Baldaquí Escandell, Ramón (1984): "El regalismo en el Semanario Erudito de Valladares", Revista de Historia Moderna. Anales de la Universidad de Alicante 4, pp. 339-386, https://dialnet.unirioja.es/servlet/ articulo? codigo=2795406 [consulta: 07/05/2018].

Bravo-Villasante, Carmen (1988): La mujer vestida de hombre en el teatro español. Madrid: Mayo de Oro.

Cabaleiro Manzanedo, Julia (1990): "María Pita: a xénese dun mito", Festa da palabra silenciada 7, pp. 99-100, https://dialnet.unirioja.es/servlet/articulo?codigo=4170902 [consulta: 02/04/2018].

Caldera, Ermanno y Antonietta Calderone (1988): "El teatro en el siglo XIX (I)", en J. M. Díez Borque (dir.), Historia del teatro en España. Madrid: Taurus, vol. 2, pp. 377-624.

Calles Hernández, Claudio (2015): La Milicia Nacional en Salamanca durante el Trienio Liberal (18201823). Salamanca: Servicio de Publicaciones de la Universidad de Salamanca, https:/gredos.usal.es/ jspui/handle/10366/128234 [consulta: 26/04/2018].

Canellas López, Ángel (1989): “La investigación histórica en España de 1830 a 1850", Historia. Instituciones. Documentos 16, pp. 255-270, https://dialnet.unirioja.es/servlet/articulo?codigo=58214 [consulta: 09/05/2018].

Cañas Murillo, Jesús (2000): Tipología de los personajes en la comedia española de buenas costumbres. Cáceres: Editorial Universidad de Extremadura, http://www.cervantesvirtual.com/obra/tipologia-de-lospersonajes-en-la-comedia-espanola-de-buenas-costumbres/ [consulta: 25/06/2018]. 
Casals Bergés, Quintí (2001): "La normativa municipal española a mediados del siglo XIX. Espacio electoral y definición social del modelo liberal en Lleida", Trienio. Ilustración y Liberalismo 38, pp. 111-154, https://repositori.udl.cat/handle/10459.1/41445 [consulta: 03/05/2018].

Cejador y Frauca, Julio (1972): Historia de la lengua y literatura castellana. Madrid: Gredos, vols. 6-7.

Coca Ramírez, Fátima (1998): "Confluencia y divergencia en la dramaturgia histórica en los siglos XVIII al XIX”, en A. López Eire, J. M. Labiano Ilundain y A. M. Seoane Pardo (eds.), Retórica, política e ideología: desde la antigüedad hasta nuestros días. Actas del II Congreso Internacional (Salamanca, noviembre 1997). Salamanca: Asociación Española de Estudios sobre Lengua, Pensamiento y Cultura Clásica, vol. 2, pp. 99-105.

- (2000): "La influencia de la 'comedia sentimental' en la poética del 'drama histórico' y de la 'tragedia neoclásica' a principios del siglo XIX en España", Cuadernos de Ilustración y Romanticismo 8, pp. 115-130, https://revistas.uca.es/index.php/cir/article/view/355 [consulta: 21/05/2018].

Díaz Marín, Pedro (1997): Las estructuras de poder durante la década moderada: Alicante, 1844-1854. Alicante: Universidad de Alicante, http://www.cervantesvirtual.com/obra/las-estructuras-de-poder-durante-la-decada-moderada-alicante-18441854--0/ [consulta: 12/04/2018].

(2006): "La construcción política de Espartero antes de su regencia, 1837-1840", Cuadernos de Ilustración y Romanticismo 14, pp. 301-327, https://revistas.uca.es/index.php/cir/article/view/31/0 [consulta: 10/05/2018].

Fernández Caamaño, José Manuel (2014): “El capitán general que se enfrentó a los ingleses”, El Ideal Gallego (A Coruña) 14/12/2014, https://www.elidealgallego.com/articulo/coruna/capitan-general-enfrentoingleses/20141214001608221422.html [consulta: 07/05/2018].

Fernández Cabezón, Rosalía (2003): "La mujer guerrera en el teatro español de fines del siglo XVIII", Anuario de Estudios Filológicos 26, pp. 117-136, https://dialnet.unirioja.es/servlet/articulo?codigo=798517 [consulta: 09/06/2018].

Ferreras, Juan Ignacio (1979): Catálogo de novelas y novelistas españoles del siglo XIX. Madrid: Ediciones Cátedra.

Ferrer Valls, Teresa (2003): "Damas enamoran damas, o el galán fingido en la comedia nueva", en F. Blas Pedraza Jiménez, E. Elisabetta Marcello y R. González Cañal (coords.), Amor y erotismo en el teatro de Lope de Vega. Actas de las XXV Jornadas de teatro clásico (Almagro, 9-11 julio 2002). Almagro: Ediciones de la Universidad de Castilla-La Mancha, pp. 191-212.

Fuente Monge, Gregorio de la (2013): "La figura del general Espartero en el teatro decimonónico", $\mathrm{Hi}$ storia y Política 29, pp. 103-138, https://dialnet.unirioja.es/servlet/articulo?codigo=4495679 [consulta: 06/05/2018].

García Garrosa, María Jesús (1991): "El comerciante inglés y El fabricante de paños: de la traducción a la adaptación”, Anales de Literatura Española 7, pp. 85-98, https://dialnet.unirioja.es/servlet/articulo? codigo $=96313$ [consulta: 22/04/2018].

(1995): “La Leandra, novela moral”, Anales de Literatura Española 11, pp. 129-142, https://dialnet.unirioja.es/servlet/articulo? codigo $=96358$ [consulta: 25/04/2018].

García Oro, José (1997): "María Pita vista por sí misma: memoriales a los Reyes Felipe II y Felipe III", Anuario Brigantino 20, pp. 23-34.

Gies, David Thatcher (1996): El teatro en la España del siglo XIX. Cambridge: Cambridge University Press.

Gómez Rodríguez, José Antonio (1998-1999): "De etnomusicología española: notas de una historia. Una aproximación al folklore musical del XVIII a través de la literatura”, Cuadernos de Estudios del Siglo XVIII 8-9, pp. 127-168, https://dialnet.unirioja.es/servlet/articulo?codigo=243554 [consulta: 07/05/2018].

González, Lola (2004): "La mujer vestida de hombre. Aproximación a una revisión del tópico a la luz de la práctica escénica”, en F. Domínguez Matito y M. L. Lobato López (coords.), Memoria de la palabra. Actas del VI Congreso de la Asociación Internacional Siglo de Oro (Burgos / La Rioja, 15-19 julio 2002). Madrid / Frankfurt: Iberoamericana / Vervuert, vol. 1, pp. 905-916, https://cvc.cervantes.es/Literatura/aiso/pdf/06/aiso_6_1_075.pdf [consulta: 15/05/2018].

González de Garay Fernández, María Teresa (1983): "De la tragedia al drama histórico: dos textos de Martínez de la Rosa”, Cuadernos de Investigación Filológica 9, pp. 199-234, https://dialnet.unirioja.es/ servlet/articulo?codigo=68950 [consulta: 09/06/2018].

González González, Luis Mariano (1995): “La mujer en el teatro del Siglo de Oro español”, Teatro. Revista de Estudios Teatrales 6-7, pp. 41-70, https://dialnet.unirioja.es/servlet/articulo?codigo=170566 [consulta: 12/06/2018]. 
Gorrochategui Santos, Luis (2011): Contra Armada. La mayor catástrofe naval de la historia de Inglaterra. Madrid: Ministerio de Defensa de España.

Herrera Navarro, Jerónimo (2005): "Don Antonio Valladares de Sotomayor: nuevos datos biográficos", Cuadernos para Investigación de la Literatura Hispánica 30, pp. 429-450, http://www.fuesp.com/ pdfs revistas/cilh/30/cilh-30-12.pdf [consulta: 14/04/2018].

Jauralde Pou, Pablo (1998): "Perspectivas en el teatro de Tirso", en Ignacio Arellano, Blanca Oteiza y Miguel Zugasti (eds.), El ingenio cómico de Tirso de Molina. Actas del II Congreso Internacional (Pamplona, 24-29 abril 1998). Pamplona: Publicaciones del Instituto de Estudios Tirsianos, pp. 157-166, http:// www.cervantesvirtual.com/obra/perspectivas-en-el-teatro-de-tirso-0/ [consulta: 20/06/2018].

Lida, Clara Eugenia (2000): "Los ecos de la república democrática y social de España. Trabajo y ciudadanía en 1848", Semata. Ciencias sociais e humanidades 12, pp. 323-338.

Llergo Ojalvo, Eva (2007): “La sociedad madrileña de 1833 a 1838 a través del teatro”, en M. C. García Tejera, I. Morales Sánchez, F. Coca Ramírez y J. A. Hernández Guerrero (eds.), Lecturas del Pensamiento Filosófico, Estético y Político. Actas del XIII Encuentro de la Ilustración al Romanticismo 1750-1850 (Cádiz, 7-9 noviembre 2006). Cádiz: Servicio de Publicaciones de la Universidad de Cádiz, pp. 27-39.

Marchena Domínguez, José (1995): "Revolución liberal en España y aproximación a su estudio en Cádiz y provincia: 'la cuestión municipal' de 1840 y el modelo portuense", Revista de Historia de El Puerto 15, pp. 81-98, https://dialnet.unirioja.es/servlet/articulo?codigo=1401661 [consulta: 07/05/2018].

Marcos Casquero, Manuel-Antonio (2001): "El sacrificio de la mujer viuda en el mundo indoeuropeo", Gerión 19, pp. 259-292, https://dialnet.unirioja.es/servlet/articulo? codigo=226970 [consulta: 24/04/2018].

Martínez de la Rosa, Francisco (1830): Obras literarias. París: Imprenta de Julio Didot.

Martínez Salazar, Andrés (1889): El cerco de La Coruña en 1589 y Mayor Fernández Pita. A Coruña: Andrés Martínez, https://archive.org/stream/elcercodelacoru00salagoog\#page/n6/mode/2up [consulta: 20/05/2018].

Navascues Benlloch, Pilar de (1996): El marqués de Cerralbo. Madrid: Dirección General de Bellas Artes y Conservación y Restauración de Bienes Culturales.

Navas-Ruiz, Ricardo (1971): El Romanticismo español. Documentos. Salamanca: Ediciones Anaya.

Navas Sánchez-Elez, María Victoria y Juan Miguel Ribera Llopis (2015): "Semanario Pintoresco Español (1836-1857): noticias sobre cultura catalana en la prensa romántica centropeninsular", Revista de Lenguas y Literaturas Catalana, Gallega y Vasca 20, pp. 71-93, https://dialnet.unirioja.es/servlet/ articulo? codigo=5313265 [consulta: 03/05/2018].

Palau y Dulcet, Antonio (1965): Manual del librero hispanoamericano. Barcelona: Librería Palau, vol. 17. Peña, Diego y Javier Martínez Pinna (2016): "La leyenda de María Pita y la heroica defensa de A Coruña", Clío. Revista de Historia 182, pp. 38-47.

Peset Reig, Mariano y José Luis Peset Reig (1967): "Legislación contra liberales en los comienzos de la década absolutista (1823-1825)", Anuario de Historia del Derecho Español 37, pp. 437-485, https:// dialnet.unirioja.es/servlet/articulo?codigo=2050649 [consulta: 06/05/2018].

Ribao Pereira, Montserrat (1999): Textos y representación del drama histórico en el Romanticismo español. Pamplona: Ediciones de la Universidad de Navarra.

Robello y Vasconi, Francisco (1856): La unión carlo-polaca o una carta de Bayona. Madrid: Imprenta de C. González.

(1865): Las dos Isabeles. Madrid: Imprenta de M. Tello.

(1867): La traición o Judas y López. Madrid: Imprenta a cargo de Ramón Moreno, http://bdh-rd. bne.es/viewer.vm?id=0000094530\&page=1 [consulta: 30/04/2018].

Rodríguez Sánchez, Tomás (1994): Catálogo de dramaturgos españoles del siglo XIX. Madrid: Fundación Universitaria Española.

Rodríguez Sánchez de León, María José (2003): “Teoría y géneros dramáticos en el siglo XIX”, en J. Huerta Calvo (coord.), Historia del teatro español. Madrid: Gredos, vol. 2, pp. 1853-1894, https://gredos. usal.es/jspui/handle/10366/124122 [consulta: 12/05/2018].

Ruiz Ramón, Francisco (1989): “Apuntes para una dramaturgia del drama histórico español del siglo XX”, en S. Neumeister (coord.), Actas del IX Congreso de la Asociación Internacional de Hispanistas (Berlín, 18-23 agosto 1986). Frankfurt: Vervuert, vol. 2, pp. 383-388, https://dialnet.unirioja.es/servlet/ articulo?codigo $=594219$ [consulta: 09/06/2018].

Saavedra Vázquez, María del Carmen (1989): María Pita y la defensa de La Coruña en 1589. A Coruña: Galicia Editorial. 
(2001): "Guerra, mujeres y movilidad social en la España moderna: el ejemplo de María Pita", en X. Balboa López y H. Pernas Oroza (coords.), Entre nós: estudios de arte, xeografía e historia en homenaxe ó profesor Xosé Manuel Pose Antelo. Santiago de Compostela: Universidade de Santiago de Compostela, pp. 339-358.

(2003): María Pita: una aproximación a su vida y a su tiempo. Perillo-Oleiros (A Coruña): Vía Láctea. (2011): María Pita. Gaxate (Pontevedra): Nigra Trea.

Sánchez García, Jesús Ángel (1992): “Arquitectura teatral en La Coruña. El siglo XIX: el teatro de la Franja o de Variedades (1823-1889)", Cuadernos de Estudios Gallegos 105, pp. 135-150, http://estudiosgallegos.revistas.csic.es/index.php/estudiosgallegos/article/viewArticle/302 [consulta: 26/04/2018].

(1992-1993): “José María Noya y el proyecto para el 'Teatro Principal' -Rosalía de Castro- de La Coruña (1838)", Revista del Instituto José Cornide 27-28, pp. 245-270.

(1993): La arquitectura teatral en Santiago de Compostela (1768-1946). Sada: Edicións do Castro.

Soheim, El Sayed El Sayed Ibrahim (1993): Don Antonio Valladares de Sotomayor, autor dramático del siglo XVIII. Madrid: Editorial de la Universidad Complutense de Madrid.

_ (1996a): "Los sainetes de Antonio Valladares de Sotomayor", en Josep María Sala Valldaura (coord.), Teatro español del siglo XVIII. Lleida: Universitat de Lleida, pp. 549-572.

(1996b): "Problemas sociales dieciochescos reflejados en el teatro de Antonio Valladares de Sotomayor", en G. Anes (coord.), El mundo hispánico en el Siglo de las Luces. Actas del Coloquio Internacional "Unidad y diversidad en el Mundo Hispánico del Siglo XVIII" (Salamanca, 9-11 junio 1994). Madrid: Universidad Complutense, vol. 2, pp. 1205-1228.

(1998): "El bandolerismo andaluz en la novela de Antonio Valladares de Sotomayor", en F. García Lara (ed.), Actas del I Congreso Internacional sobre Novela del Siglo XVIII (Almería, 28-29 noviembre 1996). Almería: Servicio de publicaciones de la Universidad de Almería, pp. 287-300.

Soraluce Blond, José Ramón (1988): "El espacio del espectáculo: los primeros teatros de Galicia”, Boletín Académico de la Escuela Técnica Superior de Arquitectura de La Coruña 9, pp. 26-37, https://ruc.udc. es/dspace/handle/2183/5169 [consulta: 02/06/2018].

Spang, Kurt (1998): El drama histórico. Teoría y comentarios. Navarra: Ediciones de la Universidad de Navarra.

Sutherland-Meier, Madeline (2009): "Antonio Valladares de Sotomayor and the 'Motín de Esquilache"”, Dieciocho. Hispanic Enlightenment 32, pp. 101-122.

(2010): "Contribuyendo a la ilustración de la nación: Valladares y el Semanario Erudito", en P. Civil y F. Crémoux (coords.), Actas del XVI Congreso de la Asociación Internacional de Hispanistas (París, 9-13 julio 2007). Madrid: Iberoamericana, vol. 2, pp. 598-602, https://cvc.cervantes.es/literatura/aih/pdf/16/aih_16_2_122.pdf [consulta: 21/04/2018].

(2013): "Censura y prensa periódica a finales del siglo XVIII. El caso del Semanario Erudito (17871791)", Revista de Literatura 150, pp. 495-514, https://dialnet.unirioja.es/servlet/articulo?codigo=4586566 [consulta: 07/05/2018].

(2014): "La Guerra de Independencia en el escenario: las comedias patrióticas de Antonio Valladares de Sotomayor", en R. Barros Roel (ed.), Actas del Coloquio Internacional "Cincuentenario de la Asociación Internacional de Hispanistas" (A Coruña, 11-13 diciembre 2012). A Coruña: Universidade da Coruña, pp. 427-434.

Tateishi, Hirotaka (2010): “El Ebusitano: el primer periódico de Ibiza en los fondos de una biblioteca americana”, Mediterranean World 20, pp. 87-109, http://hermes-ir.lib.hit-u.ac.jp/rs/bitstream/10086/19204/1/ chichukai0002000870.pdf [consulta: 08/06/2018].

Torres Molina, Marta (2018): "El cronista exiliado que defendió el honor de Ibiza”, Diario de Ibiza (Ibiza) 31/03/2018, https://www.diariodeibiza.es/pitiuses-balears/2018/03/31/cronista-exiliado-defendio-honoribiza/979206.html [consulta: 23/05/2018].

Valladares de Sotomayor, Antonio (1766): El dichoso pensador. Desagravio de las mujeres. Sus prendas, excelencias y sublimidades. Madrid: Imprenta de José Martínez Abad, http://bdh-rd.bne.es/viewer. vm?id=0000132943\&page $=1$ [consulta: 25/06/2018].

Vallejo, Irene y Pedro Ojeda (2001): El teatro en Madrid a mediados del siglo XIX. Cartelera teatral (18541864). Valladolid: Universidad de Valladolid.

Vallès Costa, Rosa (2010): "El tío Fidel, un confinat a l'Eivissa del segle XIX”, El Pitiús, pp. 146-150.

Vigo Trasancos, Alfredo Manuel (2007): A Coruña y el Siglo de las Luces. La construcción de una "Ciudad de Comercio" (1700-1808). Santiago de Compostela: Universidade de Santiago de Compostela.

Ziomek, Henryk (1983): "La dramatización veleceña de la mujer guerrera en El amor en vizcaíno", Revista de Estudios Hispánicos 17, pp. 363-370. 